Research Article

\title{
Simulating Heavy Meiyu Rainfall: A Note on the Choice of the Model Microphysics Scheme
}

\author{
Zhimin Zhou $\mathbb{D}^{\mathrm{D}},{ }^{1}$ Yi Deng $\mathbb{D}^{2},{ }^{2}$ Yang $\mathrm{Hu},{ }^{1}$ and Zhaoping $\mathrm{Kang}^{1}$ \\ ${ }^{1}$ Hubei Key Laboratory for Heavy Rain Monitoring and Warning Research, Institute of Heavy Rain, \\ China Meteorological Administration, Wuhan 430205, China \\ ${ }^{2}$ School of Earth and Atmospheric Sciences, Georgia Institute of Technology, Atlanta, GA 30332-0340, USA \\ Correspondence should be addressed to Yi Deng; yi.deng@eas.gatech.edu
}

Received 27 July 2020; Revised 30 October 2020; Accepted 11 November 2020; Published 29 November 2020

Academic Editor: Francisco Molero

Copyright ( 92020 Zhimin Zhou et al. This is an open access article distributed under the Creative Commons Attribution License, which permits unrestricted use, distribution, and reproduction in any medium, provided the original work is properly cited.

Better simulations and predictions of heavy rainfall associated with Meiyu fronts are critical for flood management in the Yangtze River Valley, China. This work systematically evaluates and compares the performances of three microphysics schemes in Weather Research and Forecasting (WRF) Model with regard to simulating properties of a classic Meiyu rainstorm in central China which occurred during a 30-hour period in July 2016, including spatial distribution, rain rate PDF, and lifecycle behavior of local rainfall. Model simulations are validated using both in situ and remote sensing observations. It is found that all three schemes capture the overall spatial distribution of precipitation and the average rainfall intensity changes more rapidly with time in the simulation than in the observation. Further insights are gained through an examination of the budget terms of raindrop and ice-phase hydrometeors in the model. Accretion of cloud droplets by raindrops and melting of ice-phase hydrometeors are the major source of rainwater. Bergeron and riming processes are found to play a prevailing role in the growth of ice-phase hydrometeors in Meiyu rainfall. Large differences in the parameterization of riming process in different schemes lead to significant differences in the simulated growth of ice-phase hydrometeors.

\section{Introduction}

Heavy rainfall in East Asia during summer is identified as Meiyu front rainfall in China. It is the main cause of meteorological disasters and often produces large-scale flooding, which brings serious about threat and loss to the economy and people's life and property in the basin $[1,2]$.

The Meiyu front is a complex of stratiform and embedded convective precipitation, which includes largescale [3,4], synoptic, and meso-scale processes [5-7]. Over the last few decades, research on the Meiyu front has mainly focused on the macroscopic characteristics, such as the structure and maintenance of the Meiyu front [8], front and frontogenesis dynamics [9], and thermodynamic characteristics $[10,11]$. In fact, the strong feedback from in-cloud microphysical processes on dynamic and thermodynamic processes of rainstorms is crucial to the evolution of the Meiyu front [12], and this feedback and microphysical processes contribute to the uncertainty of numerical models [13].

It is difficult to track the evolution of cloud microphysical processes in observations, and numerical models could be a powerful tool to investigate the microphysical characteristics of the Meiyu front. The proper representation of cloud microphysical processes is critical for numerical models. Microphysics schemes are classified into two types according to the parameterization of ice-phase hydrometeors. In typical schemes, hydrometeor categories include cloud droplet, raindrop, ice crystals, snow, and graupel (hail) [14-18]. The hydrometeor characteristics, such as bulk density, shape, and terminal fall speeds, are predefined. However, ice-phase particles have complex shapes, and the range of their densities is large, which can have a great impact on growth processes [19]. The other type of microphysics scheme includes a single ice category $[15,20]$, and uncertainties from conversions between ice-phase particles 
are eliminated. However, uncertainties from aggregation and riming efficiencies affect the performance of numerical simulations.

Although there are differences in the two types of microphysics parameterizations, both can still provide reasonable simulation results in different cases [21, 22]. Of course, the performance of precipitation simulations varies with not only the microphysics scheme but also the studied domain [23-29]. Therefore, it is crucial to investigate the microphysical characteristics of the Meiyu front's heavy rainfall due to its complexity and importance.

The sensitivity of microphysics schemes in rainfall simulations [23-26] has indicated that one scheme may provide better simulation results than others in one rainfall case, while it may provide worse results in another case. There are many causes contributing to this uncertainty, and one of the main causes is the parameterization of ice-phase microphysics. Unlike liquid hydrometeors, which are approximated by spheres, ice-phase hydrometeors have more complex shapes and a wide range of densities $[15,20]$. Therefore, microphysical processes involving ice-phase hydrometeors are very difficult to be parameterized. In fact, they have been parameterized with a highly simplified representation of nature in microphysics schemes. Although liquid-phase hydrometeors are easier to be parameterized, the interaction between liquid and ice hydrometeors will have large effects on model results. These effects depend on the parameterizations in cloud microphysics schemes. Therefore, a special goal of this study is to understand the differences in cloud microphysics schemes when simulating heavy Meiyu rainfall. The paper is organized as follows. A brief introduction to the observation data and experimental design are given in Section 2. Section 3 presents the model results and analysis. A summary and conclusions are given in Section 4.

\section{Materials and Methods}

2.1. Study Case. Several Meiyu front heavy rainfall cases during June and July 2016 have been extensively studied, and these cases have shown a certain degree of similarity. From 1200 UTC on 1 July to 1200 UTC on 2 July, a rainstorm disaster occurred (the accumulative rainfall exceeded $200 \mathrm{~mm}$ ), and the distribution of the Meiyu front was in its typical nearly zonal direction. Therefore, the following discussion will focus on this time period.

The observed large-scale circulation is shown in Figure 1. Central-eastern China is beneath the right entrance of the upper-level jet, which favors upper-level divergence and upward motion (Figure 1(a)). The southeastern part of China $\left(25-30^{\circ} \mathrm{N}, 110-120^{\circ} \mathrm{E}\right)$ is dominated by strong southwesterly winds at low levels that transport large amounts of moisture to eastern China (see Figures 1(b) and $1(\mathrm{c})$ ). Wind shear is observed over central China at $700 \mathrm{hPa}$ (Figure 1(b)), and the composite location of the Meiyu front is found along $30-32^{\circ} \mathrm{N}$ with a nearly zonal direction. The area with the maximum moisture convergence in central China is located slightly south of the Meiyu front $\left(30^{\circ} \mathrm{N}\right.$, $\left.113-115^{\circ} \mathrm{E}\right)$. In general, these large-scale circulation features are conducive to rainfall formation over central China and consistent with the typical synoptic-scale characteristics of Meiyu front systems [30, 31].

2.2. Data. The precipitation observation data used in this study are from CMORPH covering mainland China from 1200 UTC on 1 July to 1200 UTC on 2 July and are provided by the China Meteorological Administration with systematic quality control (Shen et al., 2014). There is bias varying from $-0.3 \mathrm{~mm} / \mathrm{h}$ to $0.4 \mathrm{~mm} / \mathrm{h}$ between the hourly CMORPH data and gauge data. The National Centers for Environmental Prediction (NCEP) global analysis dataset (FNL) with a coarse resolution of $1^{\circ} \times 1^{\circ}$ and a six-hour interval $(00,06,12$, and 18 UTC) provides initialization and lateral boundary conditions for the model experiments. The FNL data are also used as the background field to produce the hourly regional (i.e., central-eastern China) analysis data via the Local Analysis and Prediction System [32, 33]. The average RMSE of the geopotential height, temperature, relative humidity, wind velocity, and wind direction from LAPS are 44-45 gpm, $1.0-1.1^{\circ} \mathrm{C}, 35 \%, 2.5 \mathrm{~m} \mathrm{~s}^{-1}$, and $24-25^{\circ}$, respectively [34]. ERA5 reanalysis data with a horizontal resolution of $0.25^{\circ} \times 0.25^{\circ}$ from the European Center for Medium-Range Weather Forecasts are used to represent the observed largescale circulation.

2.3. Model Configuration. The Advanced Research WRF model (version 3.4.1) is used to conduct a series of simulations in this paper. The WRF model is run at a time step of $20 \mathrm{~s}$ and at high spatial resolution with $1200 \times 600$ grid points using a horizontal grid spacing of $3 \mathrm{~km}$ over the entire domain. The domain has 45 vertical levels and a model top of $50 \mathrm{hPa}$. Three cloud microphysics schemes are evaluated (i.e., EXP1: Morrison scheme [15]; EXP2: Thompson scheme [18]; and EXP3: Milbrandt and Yao (MY) scheme [16, 17]). Cloud microphysics processes producing hail are represented in the MY scheme. For the Morrison scheme, the focus is mainly on the evolution of the trailing stratiform region in a squall line when being implemented in the WRF model. The coefficients used in the scheme are set to graupel. One of the objectives of the Thompson scheme is to improve aviation applications to forecast aircraft icing. Hail production is not included in this scheme. The model integration starts from 0600 UTC on 1 July to 1200 UTC on 2 July, and the output from the model is at a 1-hour interval.

Table 1 summarizes the WRF physics schemes used to simulate the heavy rainfall event associated with the Meiyu front. Sensitivity tests [35] have shown that a combination of shortwave and longwave radiation schemes, PBL scheme, surface layers, and land surface schemes listed in Table 1 provide reasonable results. The number density distribution, mass-dimensional relation, and terminal velocity of hydrometeors are, respectively, expressed as follows.where $x$ denotes the hydrometeor category (i.e., $c, r, i, s$, or $g$ for droplets, rainwater, cloud ice, snow, or graupel, respectively). The characteristics of the three microphysics schemes mentioned above are compared in Table 2. Monodisperse (MONO), exponential (EXP), and gamma (GAMA) 


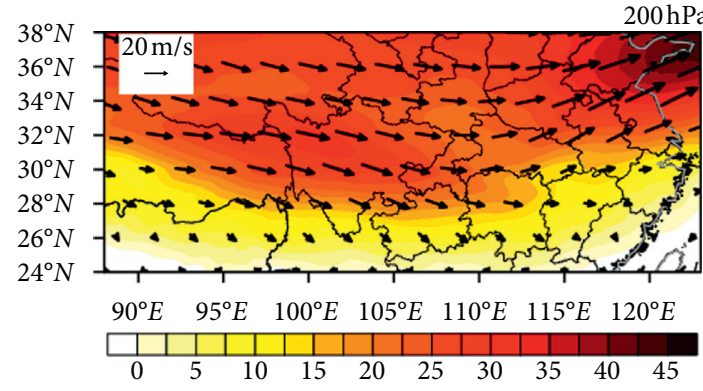

(a)

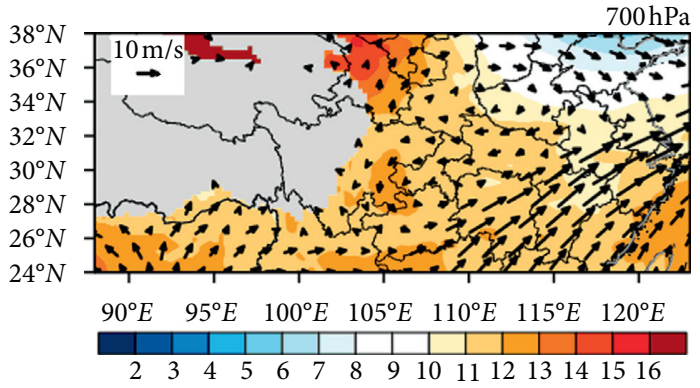

(b)

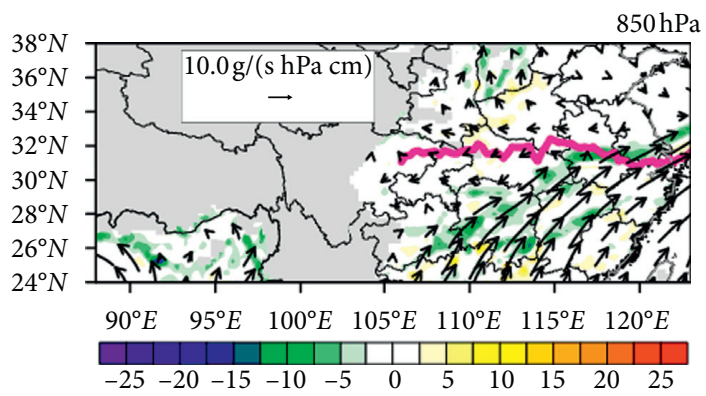

(c)

FIGURE 1: Time-mean (a) wind vectors (units: $\mathrm{m} / \mathrm{s}$ ) and zonal wind velocity (shaded; units: $\mathrm{m} / \mathrm{s}$ ) at $200 \mathrm{hPa}$, (b) wind vectors (units: $\mathrm{m} / \mathrm{s}$ ) and air temperature (units: ${ }^{\circ} \mathrm{C}$ ) at $700 \mathrm{hPa}$, and (c) moisture flux (units: $\mathrm{g} \mathrm{s}^{-1} \mathrm{hPa}^{-1} \mathrm{~cm}^{-1}$ ), moisture flux divergence (shaded; units: $10^{-7} \mathrm{~g} \mathrm{~s}^{-1} \mathrm{hPa}^{-1} \mathrm{~cm}^{-2}$ ), and the time-mean location of the Meiyu front at $850 \mathrm{hPa}$ (solid purple line).

distributions are used in these schemes. In the Morrison scheme, the coefficients can be set to graupel or hail, and they are set to graupel in this study.

$$
\begin{aligned}
N_{x} & =N_{0 x} D_{x}^{M_{x}} \exp \left(-\lambda_{x} D_{x}\right), \\
m_{x}\left(D_{x}\right) & =a_{x} D_{x}^{b_{x}}, \\
\mathrm{~V}\left(D_{x}\right) & =c_{x} D_{x}^{d_{x}} \exp \left(-\gamma_{x} D_{x}\right) .
\end{aligned}
$$

\subsection{Analysis Methods}

2.4.1. Meiyu Front Detection. The Meiyu front is a narrow convergence zone between moist and dry air masses and thus provides a favorable background for rainstorm formation. The composite location of the Meiyu front is the average location of the Meiyu front within $25-35^{\circ} \mathrm{N}$ and $106-125^{\circ} \mathrm{E}$ during this period, while the procedure of defining the location of the Meiyu front at each time step is based on locating the area with a strong gradient in the equivalent potential temperature $\left(\theta_{e}\right)$ [36] (see Figure 2): (1) we first check whether there is a band at each longitude with $\left|\left(\partial \theta_{e} / \partial \mathrm{y}\right)\right|>0.04 \mathrm{~K} / \mathrm{km}$ at $850 \mathrm{hPa}$; (2) if the band exists, the center latitude of the band at a specific longitude is then calculated; (3) a location can be defined as the Meiyu front when (a) the total number of grids with $\left(\left|\left(\partial \theta_{e} / \partial \mathrm{y}\right)\right|>0.04 \mathrm{~K} / \mathrm{km}\right)$ at all longitudes exceeds 600 , (b) the average difference in the center latitudes between adjacent longitudes is less than 1 (i.e., $\left.(1 / \mathrm{N}-1) \times \sum_{0}^{\mathrm{N}-2}|\operatorname{lat}(\mathrm{i}+1)-\operatorname{lat}(\mathrm{i})|<1\right)$, or $(\mathrm{c})$ the standard deviation of the center latitudes is less than 2.0, and the departure of the center latitudes from the averaged center latitude is less than 1.0 (i.e., $|\operatorname{lat}(\mathrm{i})-\overline{\mathrm{lat}}|<1$ ).

2.4.2. Hydrometeor Budget Analysis. Precipitation is a result of interactions among dynamics, thermodynamics, and cloud microphysics, with contributions from each factor varying across individual events [37].

For each hydrometeor species in the model, the kinetic equation for the mixing ratio $q$ is expressed as follows:

$$
\frac{\partial q}{\partial t}=-\nabla \cdot(V q)+\frac{\partial}{\partial z}\left(q \cdot V_{q x}\right)+\nabla_{D} q+\mathrm{SS},
$$

where $V$ is the $3 \mathrm{D}$ velocity vector and $V_{q x}$ is the massweighted fall speed. The terms on the right-hand side represent advection/divergence, turbulent mixing, sedimentation, and microphysical sources, respectively. The kinetic equation for the number concentration $N$ is similar. The direct effect of different microphysics schemes on the evolution of heavy rainfall is from the SS term. Despite the importance of sink and source terms, their indirect effects on the feedback of the dynamical and thermodynamic processes, which contribute to the difference in simulating accumulated rainfall, also played important roles.

Many studies have been performed which use hydrometeor budget analysis to understand cloud microphysics processes and mechanisms related to surface precipitation [37-42]. Previous work on budget analysis of precipitation has mainly focused on tropical rainfall systems, and a similar analysis has not been carried out for Meiyu front rainfall. 
TABle 1: Configuration of the WRF model considered for the simulation of rainfall.

\begin{tabular}{lc}
\hline Model options & Dataset/value \\
\hline Domains & 1 \\
Grid resolution (spacing) & $3 \mathrm{~km}$ \\
Projection system & Mercator \\
Initial conditions & NCEP FNL \\
Shortwave radiation scheme & Dudhia \\
Longwave radiation scheme & RRTM \\
PBL scheme & ACM2 \\
& 1. Morrison \\
Microphysics schemes & 2. Thompson \\
& 3. Milbrandt-Yao (MY) \\
Surface layer option & Monin-Obukhov \\
Land surface model & Noah \\
\hline
\end{tabular}

Therefore, it is necessary to analyze the budget of rain and ice-phase hydrometeors in Meiyu front rainfall.

Five microphysical processes (in which mass transfer occurs) related to the growth of raindrops are analyzed in this paper: evaporation of rain, accretion of cloud droplets by raindrops, autoconversion of cloud droplets to raindrops, riming, and melting.

Excluding the melting process, the riming and deposition (or sublimation) processes are discussed in detail. In fact, other processes related to ice-phase hydrometeors (e.g., ice nucleation, etc.) are considered. However, they play less significant roles compared to the processes mentioned above; therefore, we focus the discussion on the key processes. First, ice-phase hydrometeors are discussed as a whole to eliminate the need for conversion among ice categories. Then, deposition and riming processes related to snow and graupel are separately discussed for different cloud microphysical schemes.

\section{Results and Discussion}

3.1. Simulated Large-Scale Dynamic and Thermodynamic Characteristics. As shown in Figure 3, the large-scale circulation characteristics are reasonably reproduced in all three experiments with different microphysics schemes, which increases the confidence in further analysis of the microphysical processes. Despite the good performances of all experiments in simulating the large-scale circulation pattern, weak biases can be found in the composite location of the Meiyu front. These biases may be ascribed to local thermal and dynamical differences, which are associated with the selected cloud microphysical scheme.

\subsection{Observed and Simulated Precipitation Characteristics.} Figure 4 shows the spatial distribution of the cumulative rainfall within 24 hours (Rain24) over central China according to the observations and the WRF simulations with different microphysics schemes.

Here, the model outputs are interpolated to a resolution of 0.1 degrees for comparison with the observations. An initial comparison of these three figures shows that the structure and location of precipitation are fairly similar among the three schemes. In fact, the rainfall intensity from the model output, especially in the heavy rainfall area (i.e., where Rain 24 exceeds $50 \mathrm{~mm}$ ), is overestimated compared to observations. It can be seen that a spatial bias exists for the modeled heavy rainfall area, and the coverage of the region receiving heavy rainfall is overestimated in the models. Compared with the observations, the simulated rain belts are located slightly south over central-eastern China $\left(113-115^{\circ} E\right)$. The root mean square errors (RMSE) of model results are calculated. For Morrison, Thompson, and MY schemes, the value of RMSE is $0.263 \mathrm{~mm}, 0.258 \mathrm{~mm}$, and $0.261 \mathrm{~mm}$, respectively.

Regarding the model results, Rain24 is overestimated over the lower reaches of the Yangtze River $\left(117-119^{\circ} \mathrm{E}\right)$, especially in the MY scheme. The Thompson scheme produces the weakest rainfall, especially between $25^{\circ} \mathrm{N}$ and $27^{\circ} \mathrm{N}$.

The empirical probability density function (PDF) distributions of precipitation obtained from the WRF simulations are compared to the observed precipitation (see Figure 5). Figure 5 follows the same interpolation method as Figure 4 . The data in this figure are normalized by the total number of model grid points to ensure a fair comparison between the PDFs of the WRF simulations and observations. The comparison results show that the model overestimates nearly all rain categories with a cumulative precipitation in 24 hours (Rain24) greater than $0.1 \mathrm{~mm}$ except for Rain24 cases of $10-50 \mathrm{~mm}$. In a comparison of model outputs, the Morrison scheme simulates the highest percentage of rain except for when Rain $24<10 \mathrm{~mm}$. The difference in Rain 24 between the MY and Morrison schemes is small for light rainfall (i.e., Rain 24 ranging from 0.1 to $10 \mathrm{~mm}$ ). The Thompson scheme produces the lightest Rain24 except for when Rain24 is between 10 and $100 \mathrm{~mm}$. In fact, the difference in Rain 24 between the MY and Thompson schemes is not obvious. The model overestimates the percentage of drizzle (i.e., Rain $24<0.1 \mathrm{~mm}$ ), which may be partly caused by the limitation of the sensors of rain-gauge instruments $[43,44]$.

\subsection{Comparison of Average Rainfall Amount and Mean Mass} Concentration of Rain in the Heavy Rainfall Area. Figure 6 compares the 24-hour time series of the average rainfall intensity (ave-Rain, hereafter) and the averaged rainwater content (ave-Qr, vertically and horizontally averaged) in the heavy rainfall area between the model outputs and observations. Figure 6(a) shows that rainfall starts slowly but maintains a relatively steady intensity throughout the period in the observations, while, in the model simulations, rainfall starts rapidly (from 1200 to 1400 UTC on 1 July), gaining strength at the very beginning but dissipating rapidly from 0200 UTC on 2 July.

It can be seen from Figure 6(b) that the time evolutions of ave-Rain and ave-Qr are consistent in most time periods, especially when they change rapidly. Moreover, ave-Qr from the Morrison scheme experiences the most abrupt evolution, and ave-Qr from the Thompson scheme shows a relatively smooth evolution compared to the other two schemes. The MY scheme simulates more ave-Rain than the Morrison 
TABle 2: Summary of hydrometeor size distributions in the Morrison, Thompson, and MY schemes.

\begin{tabular}{|c|c|c|c|c|c|c|c|c|c|c|}
\hline Scheme & Category & Distribution & $N_{0 x}\left(\mathrm{~m}^{-4}\right)$ & $\begin{array}{c}a_{x} \\
\left(m^{-b_{x}}\right)\end{array}$ & $b_{x}$ & $c_{x}\left(m s^{-1} m^{-d_{x}}\right)$ & $d_{x}$ & $\rho_{x}$ & $\gamma_{x}$ & $M_{x}$ \\
\hline \multirow[t]{5}{*}{ Morrison } & Cloud & GAMA & $\begin{array}{c}\text { Varies to } \\
\text { maintain a } \\
\text { constant total } \\
\text { number } \\
\text { density of } \\
250 \times 10^{6} \\
\left(\mathrm{~m}^{-3}\right)\end{array}$ & $\pi \rho_{c} / 6$ & 3 & $3 \times 10^{7}$ & 2 & 997 & 0 & $\begin{array}{l}\text { Dependent on droplet } \\
\text { number density }\end{array}$ \\
\hline & Rain & EXP & Prognostic & $\pi \rho_{r} / 6$ & 3 & 841.99667 & 0.8 & 997 & 0 & 0 \\
\hline & Ice & EXP & Prognostic & $\pi \rho_{i} / 6$ & 3 & 700 & 1 & 500 & 0 & 0 \\
\hline & Snow & EXP & Prognostic & $\pi \rho_{s} / 6$ & 3 & 11.72 & 0.41 & 100 & 0 & 0 \\
\hline & Graupel & EXP & Prognostic & $\pi \rho_{g} / 6$ & 3 & 19.3 & 0.37 & 400 & 0 & 0 \\
\hline \multirow{5}{*}{ Thompson } & Cloud & GAMA & $100 \times 10^{6}$ & $\pi \rho_{c} / 6$ & 3 & 0 & 0 & 1000 & 195 & $\operatorname{Min}\left(15\left(10^{9} / N_{0 c}\right)+2\right)$ \\
\hline & Rain & EXP & Prognostic & $\pi \rho_{r} / 6$ & 3 & 4854.0 & 1 & 1000 & 195 & 0 \\
\hline & Ice & EXP & Prognostic & $\pi \rho_{i} / 6$ & 3 & 1847.5 & 1 & 890 & 0 & 0 \\
\hline & Snow & $\mathrm{EXP}+\mathrm{GAMA}$ & $\begin{array}{l}\text { Temperature- } \\
\text { dependent }\end{array}$ & 0.069 & 3 & 40 & 0.55 & $\begin{array}{c}\text { Varies } \\
\text { with } \\
\text { D }^{\mathrm{d}}\end{array}$ & 100 & 0.636 \\
\hline & Graupel & EXP & $\begin{array}{l}\text { Varies } \\
\text { according to a } \\
\text { function of } \\
\text { total mass } \\
\text { and size } \\
\text { distribution }\end{array}$ & $\pi \rho_{g} / 6$ & 3 & 442 & 0.89 & 500 & 0 & 0 \\
\hline \multirow[t]{5}{*}{ MY } & Cloud & GAMA & $\begin{array}{c}\text { Varies to } \\
\text { maintain a } \\
\text { constant total } \\
\text { number } \\
\text { density of } \\
200 \times 10^{6} \\
\left(\mathrm{~m}^{-3}\right)\end{array}$ & $\pi \rho_{c} / 6$ & 3 & 0 & 0 & 1000 & 0 & 0 \\
\hline & Rain & EXP & Prognostic & $\pi \rho_{r} / 6$ & 3 & 149.1 & 0.5 & 1000 & 0 & 0 \\
\hline & Ice & EXP & Prognostic & 440 & 3 & 71.34 & 0.6635 & 500 & 0 & 0 \\
\hline & Snow & EXP & Prognostic & 0.1597 & 2.08 & 11.72 & 0.41 & $\begin{array}{l}\text { Varies } \\
\text { with } D\end{array}$ & 0 & 0 \\
\hline & Graupel & EXP & Prognostic & $\pi \rho_{g} / 6$ & 3 & 19.3 & 0.37 & 400 & 0 & 0 \\
\hline
\end{tabular}

scheme during most of the simulation time, while the former simulates less ave-Qr before 0200 UTC on 2 July. The Thompson scheme simulates the smallest ave-Rain, which coincides with the ave-Qr. This demonstrates that a larger amount of ave-Qr is not always consistent with more aveRain. After all, ave-Qr includes the distribution of raindrops at different levels, while ave-Rain only includes the distribution of raindrops at the surface. Regardless, the time evolution of precipitation and raindrop content shows good consistency during most of the time period.

Figure 7 shows the spatial distributions of the standard deviation of the geopotential height over central-eastern China at $700 \mathrm{hPa}$ and $500 \mathrm{hPa}$ based on hourly regional analysis data (i.e., LAPS product). Generally, a relatively low standard deviation is found over the entire domain (i.e., central China) at $700 \mathrm{hPa}$ except for the maximum values found near the coastline of the Yellow Sea, indicating an overall slow evolution of the synoptic-scale circulation over central China during this period.

In addition, a maximum at $500 \mathrm{hPa}$ is found over Hubei province $\left(30-32^{\circ} \mathrm{N}, 110-114^{\circ} \mathrm{E}\right)$, consistent with the development/decay of the rainfall system over this area. The spatial patterns of the standard deviation in the three experiments are generally in agreement with the observations with the following biases: the center at $500 \mathrm{hPa}$ in all experiments is located west of that in the analysis data (see Figures 8 and 9). The modeled geopotential height over central-eastern China has greater temporal variability than that observed during this period (see Figure 9), which is consistent with the greaterthan-observed rainfall temporal variability in the models. 


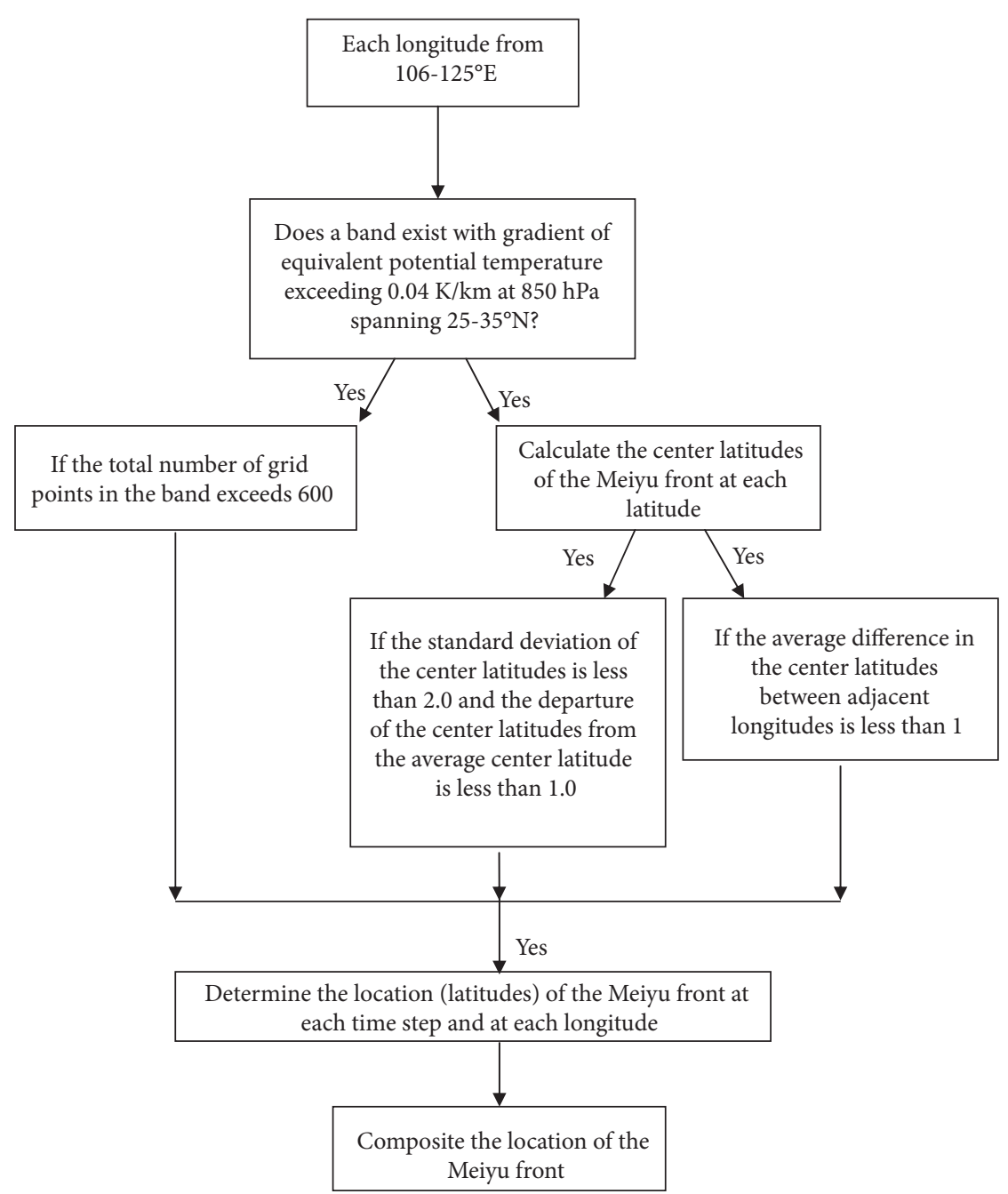

FIGURE 2: Flow chart determining the composite location of the Meiyu front.

3.4. Budget Analysis of Raindrops. A comparison shows that the microphysics processes involved in raindrop growth mainly include the evaporation of rain (Evap), the riming of raindrops by ice-phase hydrometeors (Col1), the autoconversion of cloud droplets to rain (Auto), the accretion of cloud droplets by raindrops (CLcr), and the melting of icephase hydrometeors (Mlt). The accretion of raindrops by frozen particles is neglected because of the relatively small magnitude of the transferred mass.

Figure 10 shows the time series of the mean content of the main sources and sinks of rain (computed with the same method as ave-Rain in Figure 6) in the heavy rainfall area. For brevity, the prefix "ave-" is used to represent the mean content of the mass transferred through different microphysical processes. The simulation results from all three microphysics schemes indicate the importance of Mlt and CLcr, which appear to play dominant roles in the growth of raindrops. The melting of ice-phase hydrometeors to form rain is called the "cold-rain" microphysics mechanism. This mechanism is important in Meiyu front precipitation [21].

Although simulations using all three microphysics schemes demonstrate the importance of Mlt and CLcr for Meiyu front precipitation, the detailed roles Mlt and CLcr play in the temporal evolution of rainfall are different in each scheme. In the Morrison scheme (see Figure 10(a)), aveCLcr is larger than ave-Mlt before 0200 UTC on 2 July, and the latter is larger than the former from 0200 UTC to 0500 UTC on 2 July. During the remaining period, ave-CLcr is slightly larger than ave-Mlt. In the Thompson scheme (see Figure 10(b)), ave-CLcr is larger than ave-Mlt before 2300 UTC on 1 July and then less than ave-Mlt after that time. The MY scheme simulates more ave-Mlt than ave-CLcr throughout most of the simulation period.

In contrast, ave-Coll is approximately several times smaller than the other two processes in the Morrison and 


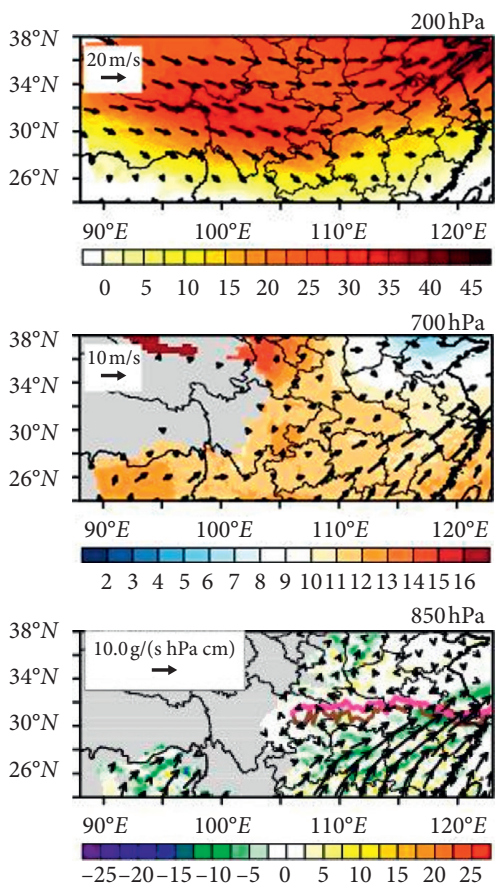

(a)

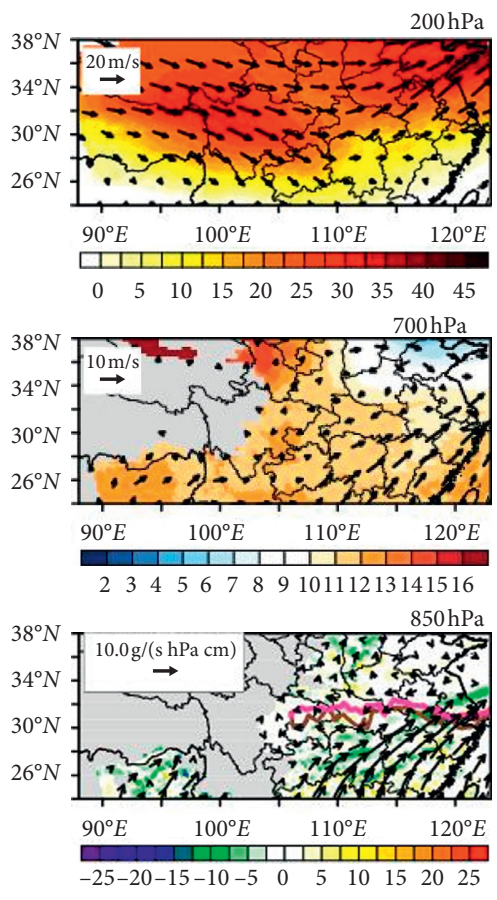

(b)
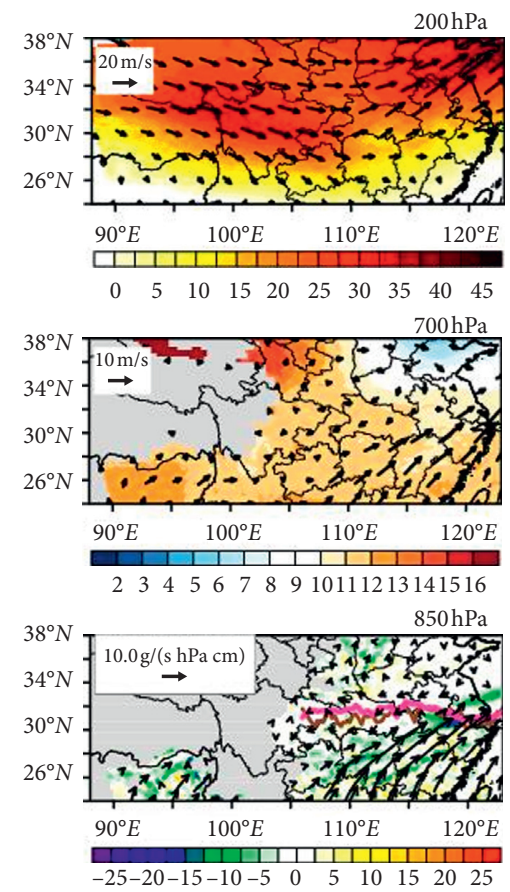

(c)

Figure 3: The same as Figure 1 except for the model output with the composite location of the Meiyu front in each experiment (observations) being indicated by a solid brown (purple) line.

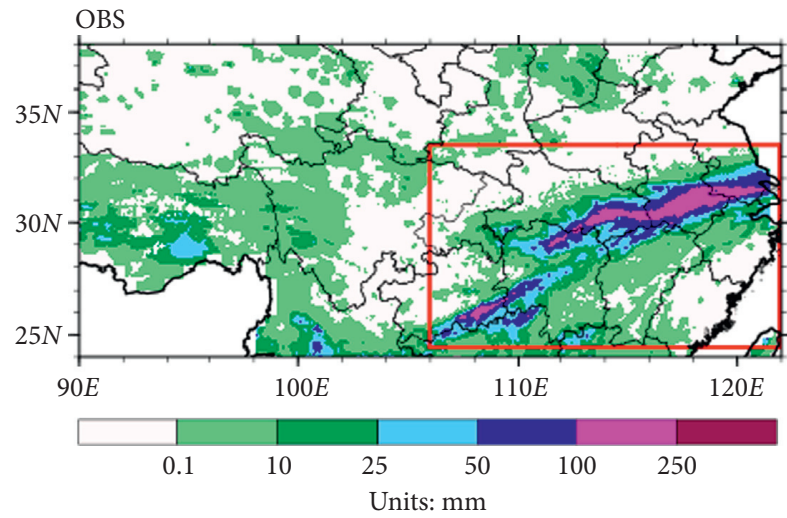

(a)

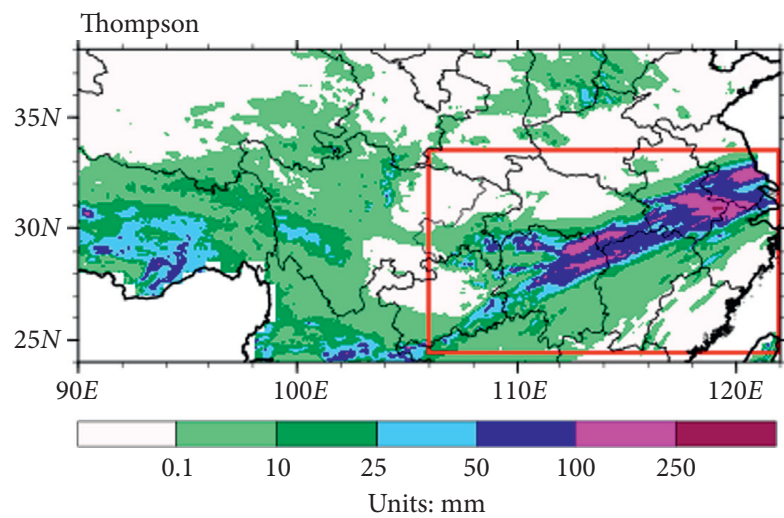

(c)

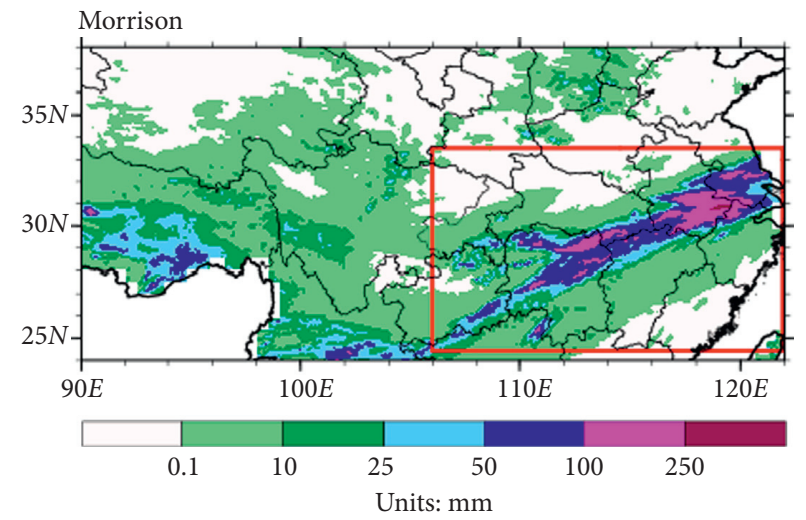

(b)

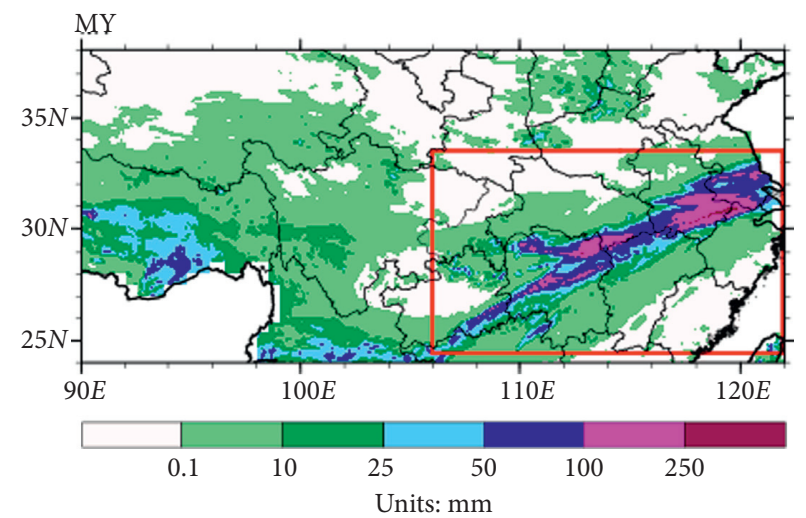

(d)

FIGURE 4: Spatial distribution of cumulative rainfall in 24 hours for (a) the observations and ((b)-(d)) the WRF simulations using three microphysics schemes: (b) Morrison, (c) Thompson, and (d) MY. 


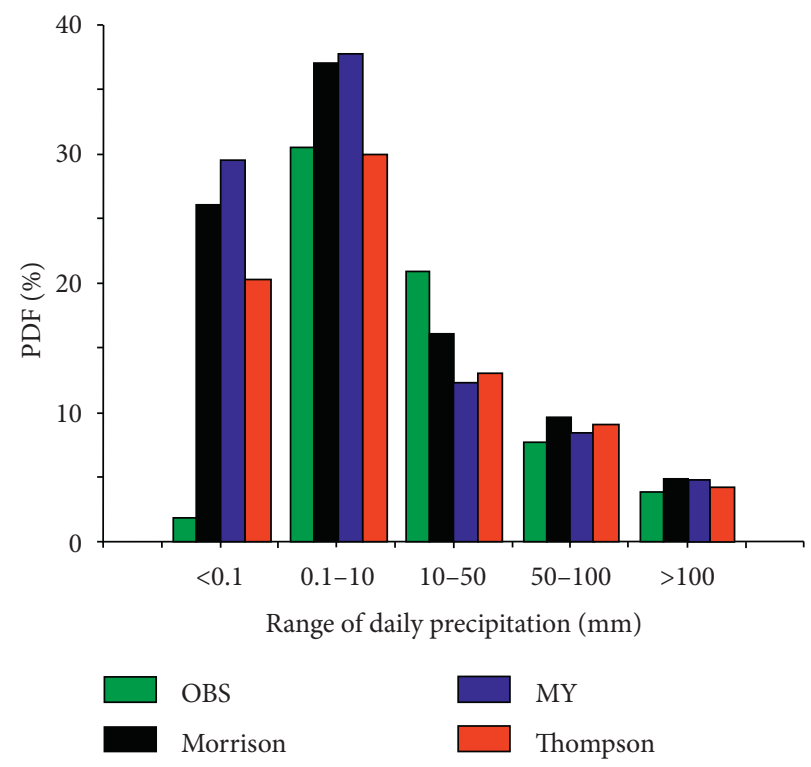

FIGURE 5: PDFs of the cumulative precipitation in 24 hours between the observations and WRF simulations using the three microphysics schemes (Morrison, Thompson, and MY).

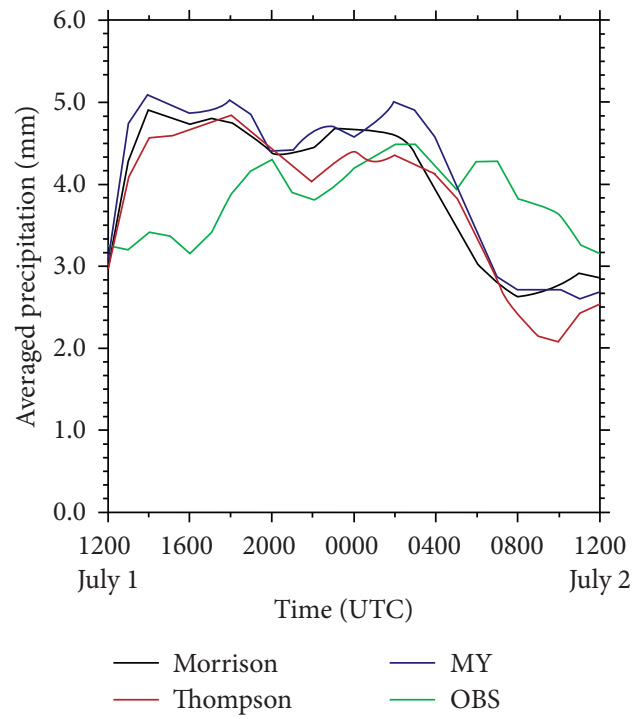

(a)

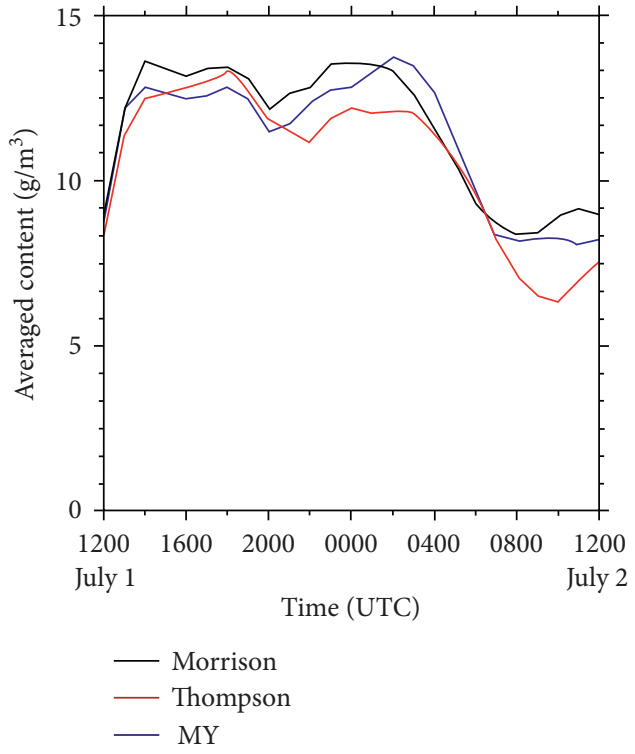

(b)

Figure 6: Time series of (a) area-averaged rainfall and (b) rainwater content in a heavy rainfall area of observation and simulation results from 1200 UTC on 1 July to 1200 UTC on 2 July 2016.

Thompson schemes. The MY scheme produces a larger aveAuto than the other two schemes, although ave-Auto is still an order of magnitude smaller than ave-Mlt and ave-CLcr.

The simulation results suggest that the dominant source terms of rain are the melting of ice-phase hydrometeors and accretion of cloud droplets by raindrops. The key sink term is the evaporation of raindrops. The differences in evaporation processes for these 3 schemes are relatively small.

Figure 11 shows the vertically averaged content of transferred mass from the melting of ice-phase hydrometeors (h_ave_Mlt) and accretion of cloud droplets by raindrops (h_ave_CLcr). 


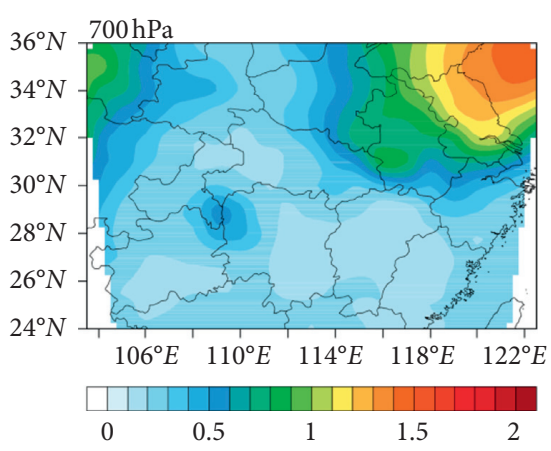

(a)

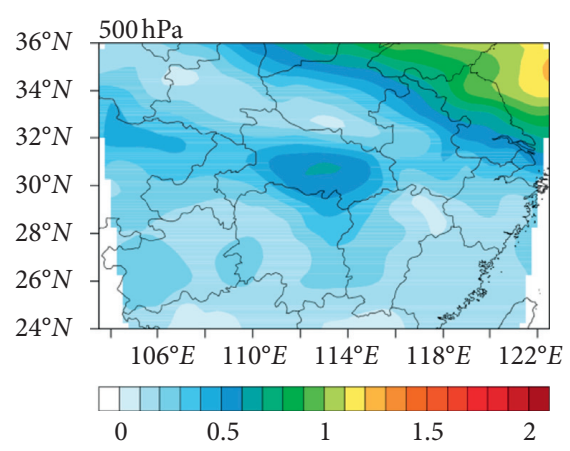

(b)

FIGURE 7: The spatial distribution of the standard deviation of the geopotential height (units: $10 \times \mathrm{gpm}$ ) at (a) $700 \mathrm{hPa}$ and (b) $500 \mathrm{hPa}$ from 1 July to 2 July 2016.

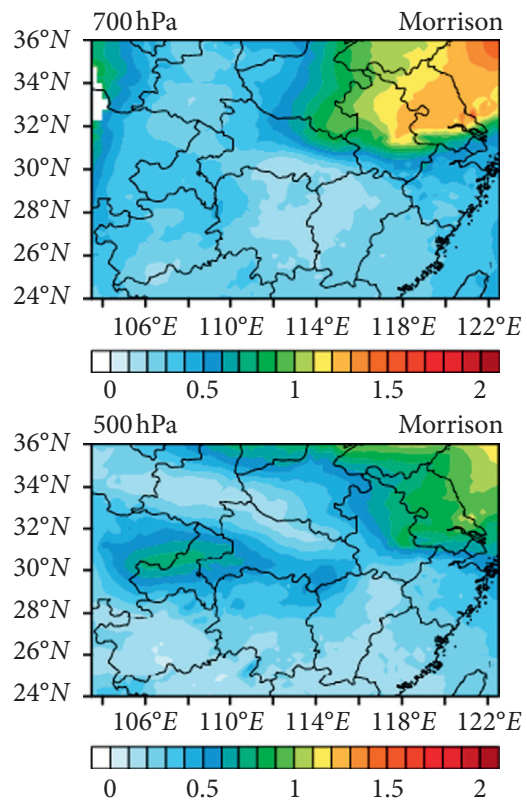

(a)
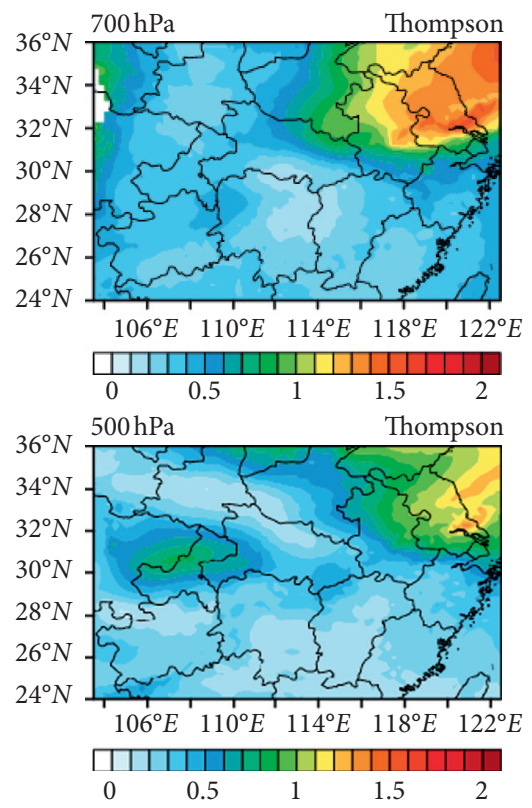

(b)

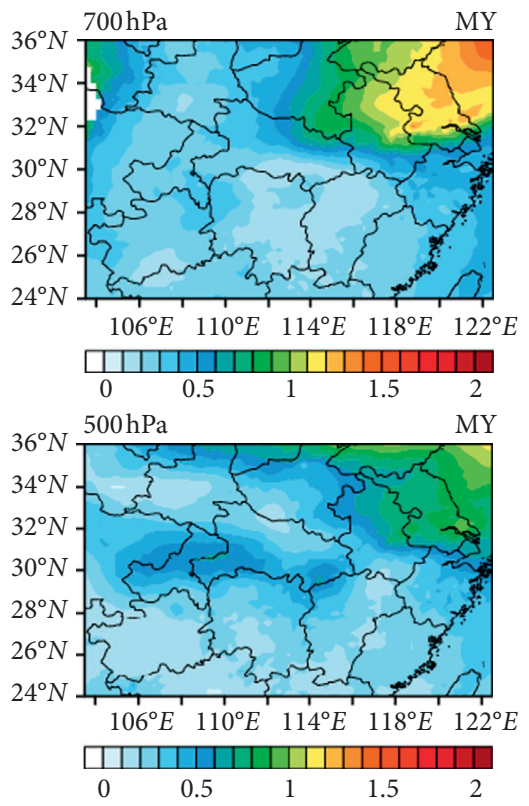

(c)

Figure 8: The same as Figure 7 except for the three experiments: (a) Morrison, (b) Thompson, and (c) MY. 1 and 2 indicate 700 hPa and $500 \mathrm{hPa}$, respectively.

It can be seen that differences in $\mathrm{h} \_$ave_Mlt and h_ave_CLcr exist in local areas for all schemes. Even in one scheme, there are obvious differences in h_ave_Mlt and h_ave_CLcr. Compared with Figure 4, the maximum h_ave_Mlt and h_ave_CLcr values are consistent with the maximum cumulative precipitation. This indicates that the difference in the two key microphysical processes in different microphysics schemes leads to the differences in the spatial distribution of heavy rainfall, especially in the maximum cumulative rainfall area.

Table 3 shows the simulated ave-Rain, ave-Mlt, ave-CLcr, and ave-Evap trends in two continuous time periods, which represent the rapid increase and decrease periods of precipitation.
From 1200 to 1400 UTC on 1 July, precipitation experiences a sharp increase. The evolution of two key processes (melting of ice-phase hydrometeors and accretion of cloud droplets by raindrops) in all three schemes shows good consistency with the evolution of precipitation. The ave-Rain trend differs in three schemes from 1400 to 1500 UTC on 1 July. The three key processes show similar trends with aveRain in the Thompson scheme, although they differ in the other two schemes. The precipitation experiences a sharp decrease from 0300 to 0600 UTC on 2 July. During this time period, the ave-Mlt and ave-CLcr trends are nearly consistent with that of ave-Rain in the MY scheme. In the other two schemes, ave-Mlt and ave-CLcr show opposite trends in 

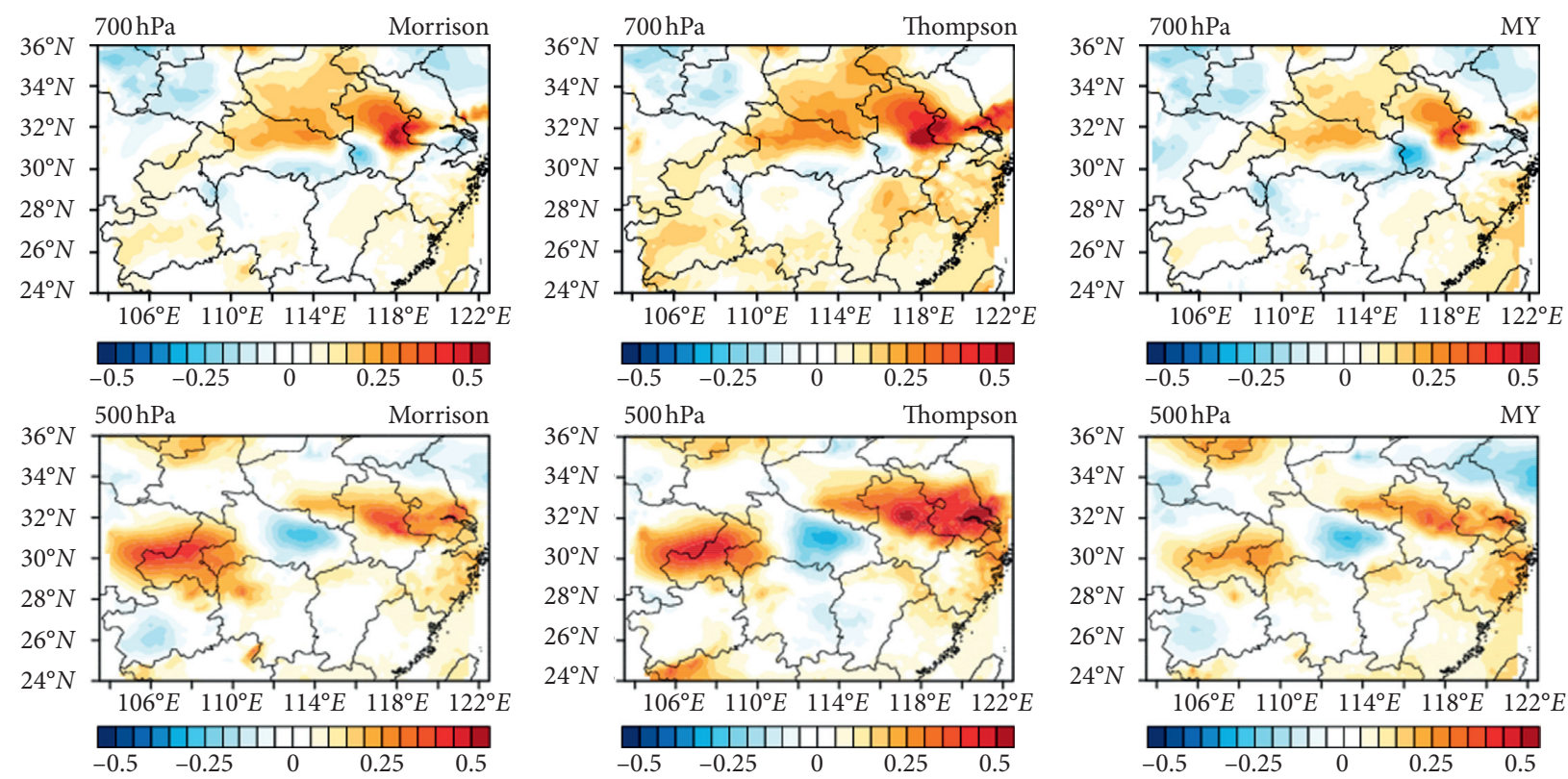

(a)

(b)

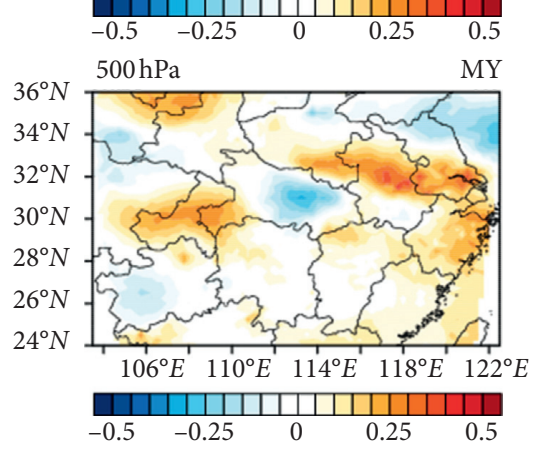

(c)

FIgURE 9: The same as Figure 8 except for the differences between the model output and LAPS product (Model-LAPS).

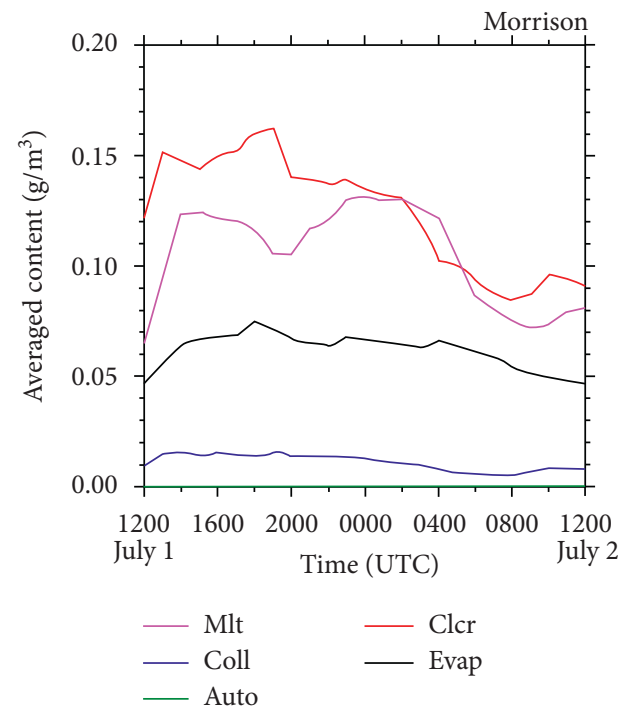

(a)

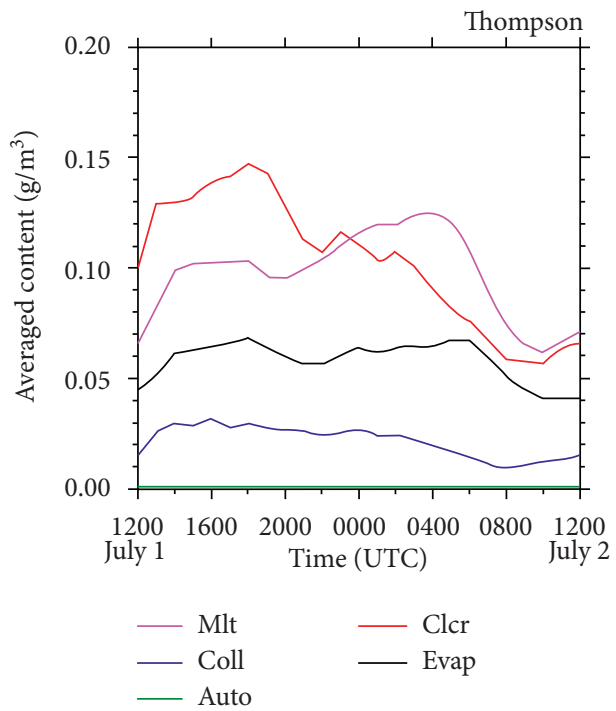

(b)

FIgURe 10: Continued. 


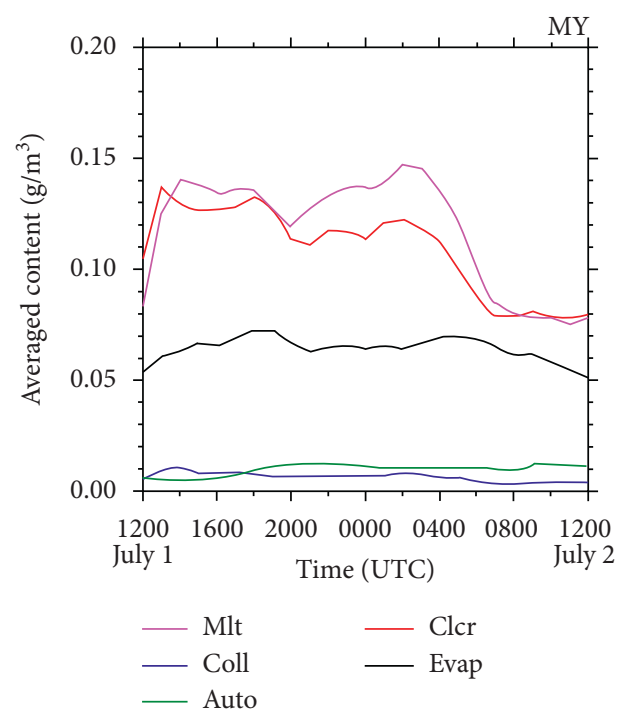

(c)

FIgURE 10: Time series of the mean content of the main sources and sinks of rain in heavy rainfall areas from 1200 UTC on 1 July to 1200 UTC on 2 July in 2016: (a) Morrison, (b) Thompson, and (c) MY.

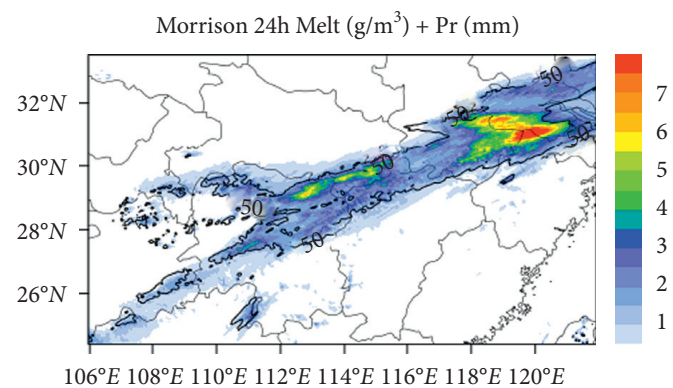

(a)
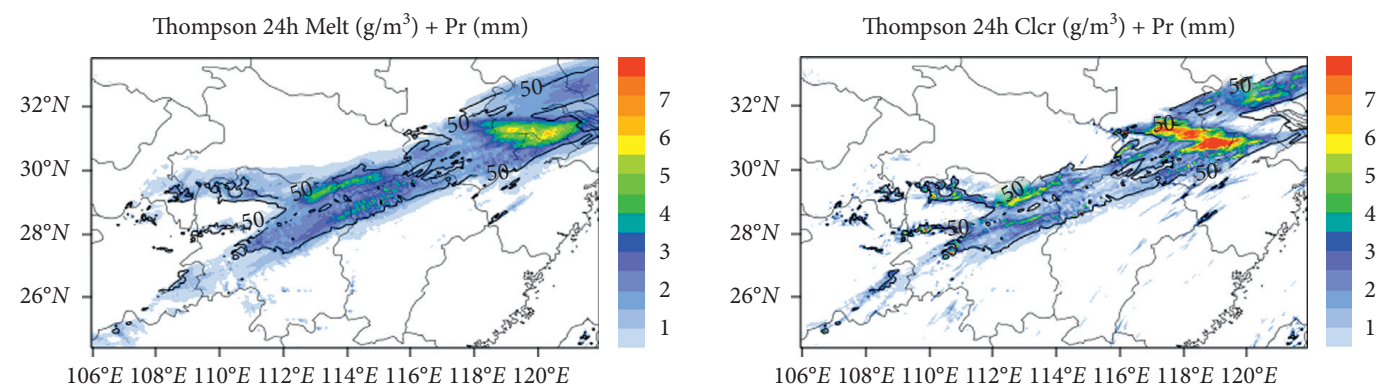

(b)
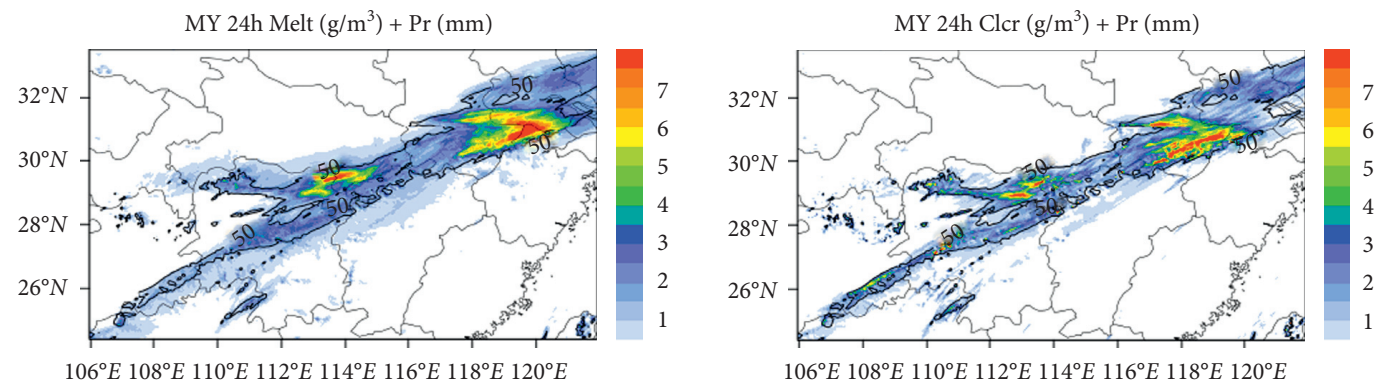

(c)

FIGURE 11: Vertically averaged h_ave_Mlt and h_ave_CLcr (shaded area) and heavy rainfall area (contour of $50 \mathrm{~mm}$ ): (a), Morrison; (b) Thompson; (c) MY. 1 and 2 indicate melting of ice-phase hydrometeors and accretion of cloud droplet by rain, respectively. 
TABLE 3: Simulated ave-Rain, ave-Mlt, ave-CLcr, and ave-Evap trends from 1200 to 1500 UTC on 1 July and from 0300 to 0600 UTC on 2 July. Red upward arrows and blue downward arrows represent increases and decreases, respectively. “-” indicates a negligible change.

\begin{tabular}{|c|c|c|c|c|c|c|c|c|c|c|c|c|}
\hline \multirow{2}{*}{ Time } & \multicolumn{4}{|c|}{ Morrison } & \multicolumn{4}{|c|}{ Thompson } & \multicolumn{4}{|c|}{ MY } \\
\hline & Prec & Mlt & CLcr & Evap & Prec & Mlt & CLcr & Evap & Prec & Mlt & CLcr & Evap \\
\hline $12 \mathrm{z} 01-13 \mathrm{z} 01$ & $\uparrow$ & $\uparrow$ & $\uparrow$ & $\uparrow$ & $\uparrow$ & $\uparrow$ & $\uparrow$ & $\uparrow$ & $\uparrow$ & $\uparrow$ & $\uparrow$ & $\uparrow$ \\
\hline $13 z 01-14 z 01$ & $\uparrow$ & $\uparrow$ & $\uparrow$ & $\uparrow$ & $\uparrow$ & $\uparrow$ & $\uparrow$ & $\uparrow$ & $\uparrow$ & $\uparrow$ & $\uparrow$ & $\uparrow$ \\
\hline $14 z 01-15 z 01$ & $\downarrow$ & $\uparrow$ & - & $\uparrow$ & $\uparrow$ & $\uparrow$ & $\uparrow$ & $\uparrow$ & $\downarrow$ & $\downarrow$ & - & $\uparrow$ \\
\hline 03Z02-04Z02 & $\downarrow$ & $\downarrow$ & $\downarrow$ & - & $\downarrow$ & $\uparrow$ & $\downarrow$ & - & $\downarrow$ & $\downarrow$ & $\downarrow$ & - \\
\hline 04Z02-05Z02 & $\downarrow$ & $\downarrow$ & $\downarrow$ & $\downarrow$ & $\downarrow$ & $\downarrow$ & $\downarrow$ & $\uparrow$ & $\downarrow$ & $\downarrow$ & $\downarrow$ & - \\
\hline 05Z02-06Z02 & $\downarrow$ & $\downarrow$ & $\uparrow$ & $\downarrow$ & $\downarrow$ & $\downarrow$ & $\downarrow$ & $\uparrow$ & $\downarrow$ & $\downarrow$ & $\downarrow$ & - \\
\hline
\end{tabular}

some time periods. Moreover, ave-Evap does not change as rapidly as the other two processes.

These two different evolution periods of precipitation indicate that the trend in key processes is still not consistent with that of ave-Rain when ave-Rain experiences rapid changes, and the microphysical parameterization scheme affects the consistency between processes and precipitation.

\subsection{Budget Analysis of Ice-Phase Hydrometeors. Previous} studies have shown that the coexistence and interaction of ice-phase and liquid-phase hydrometeors in mixed-phase cloud processes contribute most to the formation and development of heavy rainfall in Meiyu frontal systems [21]. To simplify the discussion, all ice categories are considered as a whole. Except for melting (Mlt) and evaporation deposition (VD), Coll and the collision of cloud droplets with ice-phase hydrometeors (Col2) are discussed. Similar to Figure 6, the prefix "ave-" is used to represent the mean content of transferred mass by different sink and source terms.

Figure 12 indicates that there are similarities in the evolution of the key budget terms of raindrops in all microphysics schemes, especially when rapid changes occur.

The MY and Thompson schemes simulate the largest and least amounts of melted ice-phase hydrometeors, respectively (see Figure 12(a)). The ave-Des values simulated by the Morrison and Thompson schemes, which are larger than those simulated by the MY scheme (see Figure 12(b)), show similar temporal evolutions. Cloud droplets contribute more than raindrops to the growth of ice-phase hydrometeors in the riming process (see Figures 12(c) and 12(d)). Because cloud droplets are smaller and lighter than raindrops, it is easier for the former to be lifted to high levels and collide with ice-phase hydrometeors. Therefore, ave-Col2 is larger than ave-Col1, especially in the MY scheme, in which aveCol2 is several times larger than ave-Col1.

For the Morrison and Thompson schemes, deposition and riming processes play nearly equally important roles, while the riming of cloud droplets by ice-phase hydrometeors contributes more than deposition. This demonstrates that the contribution of the same cloud microphysical processes may be very different across different parameterization schemes.

As mentioned above, precipitation increases (decreases) from 1200 to 1500 UTC on 1 July (0300 to 0500 UTC on 2 July), while the ice-phase hydrometeors experience similar evolutions during the two time periods. To further understand the results shown in Figure 6, Table 4 compares the changes in the simulated ave-Mlt, ave-Dep, ave-Col1, and ave-Col2 during these two time periods, similar to Table 2.

From 1200 to 1400 UTC on 1 July, ave-Rain and ave-Qr increase rapidly. All three schemes simulate the same aveMlt, ave-Dep, ave-Col1, and ave-Col2 trends. From 1400 to 1500 UTC on 1 July, ave-Rain and ave-Qr from the Thompson scheme do not change as rapidly as those in the previous time period, and the changes in the four sink and source terms of rain do not show good consistency. The consistency in the other two schemes is better than that of the Thompson scheme. During the time period when aveRain and ave-Qr decrease rapidly (from 0300 to 0600 UTC on 2 July), the trends in the four budget terms show good consistency. This demonstrates that when the precipitation and water content experience rapid changes, the trends in the sink and source terms of ice-phase hydrometeors are largely consistent.

Figure 13 compares the contributions of snow and graupel to riming. Collisions between cloud droplets (raindrops) and snow are represented by CLcs (CLrs), and CLcg (CLrg) indicates the collision between cloud droplets (raindrops) and graupel. The meaning of the prefix "ave-"is the same as that mentioned above.

It can be seen that graupel and snow contribute very differently to the riming process in different schemes. The accretion of cloud droplets by snow and graupel is the major cause of growth in the Morrison scheme. The accretion of cloud droplets by snow (graupel) is the major cause of growth in the Thompson (MY) scheme. Moreover, ave-CLrs is much smaller than the other terms and is nearly negligible, especially in the MY scheme. The Morrison scheme simulates more ave-CLcg than aveCLcs in general and more ave-CLcs than ave-CLcg from 0300 to 1000 UTC on 2 July (see Figure 13(a)). This scheme simulates more ave-CLrg than ave-CLrs at the same time, and they are less than the other two source terms of ice-phase hydrometeors. Compared to the Thompson scheme, which produces more ave-CLcs than ave-CLcg over the entire time period (see Figure 13(b)), the MY scheme simulates very different results (see Figure 13(c)); for example, ave-CLcg is nearly an order of magnitude larger than ave-CLcs. Consequently, more snow is simulated in the Thompson scheme, and more graupel is simulated in the MY scheme (see Figure 14).

These results demonstrate that great differences in the riming process of different cloud microphysics schemes may be one of the major causes leading to distribution differences 

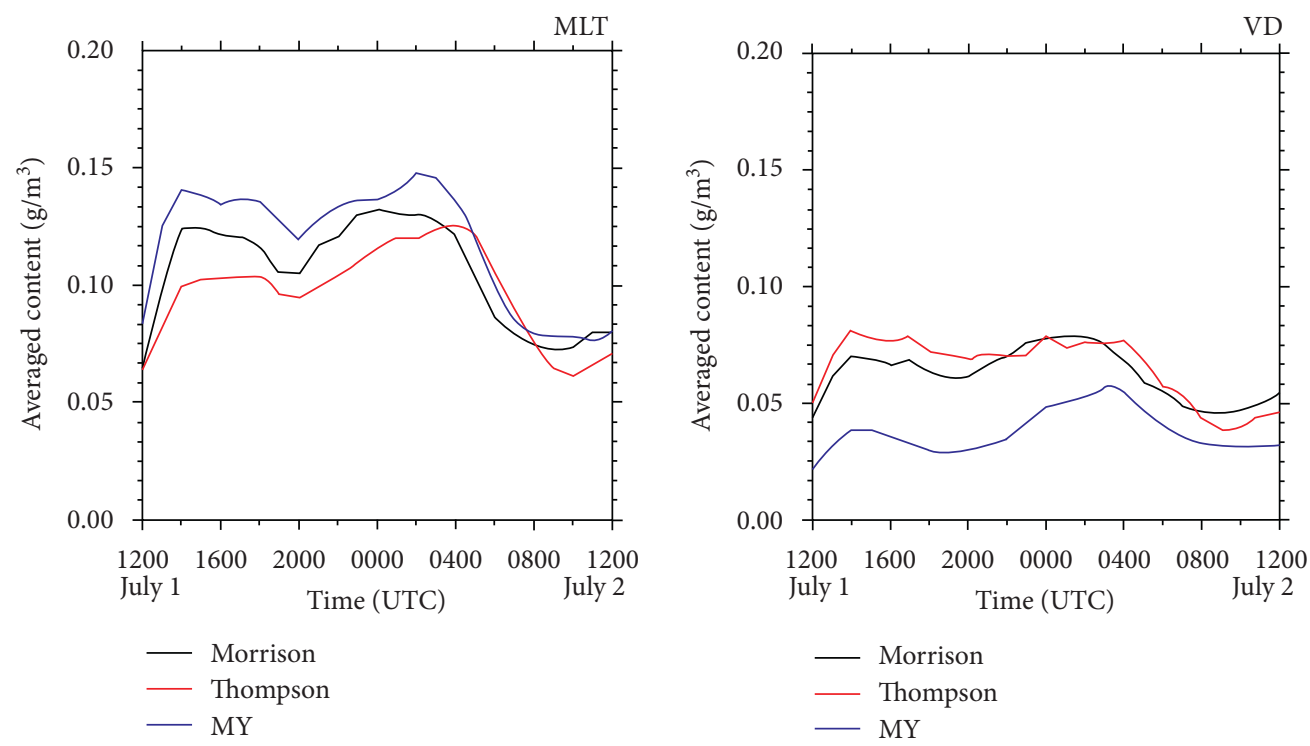

(a)

(b)

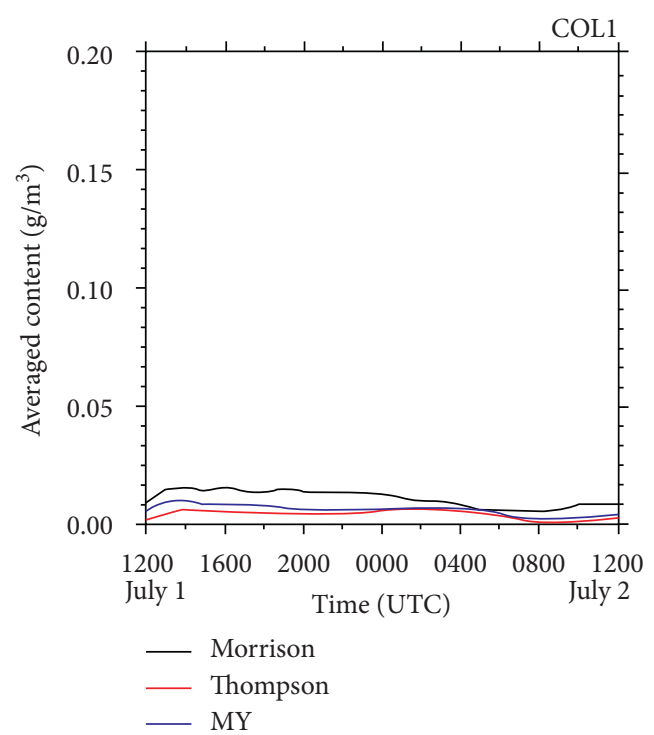

(c)

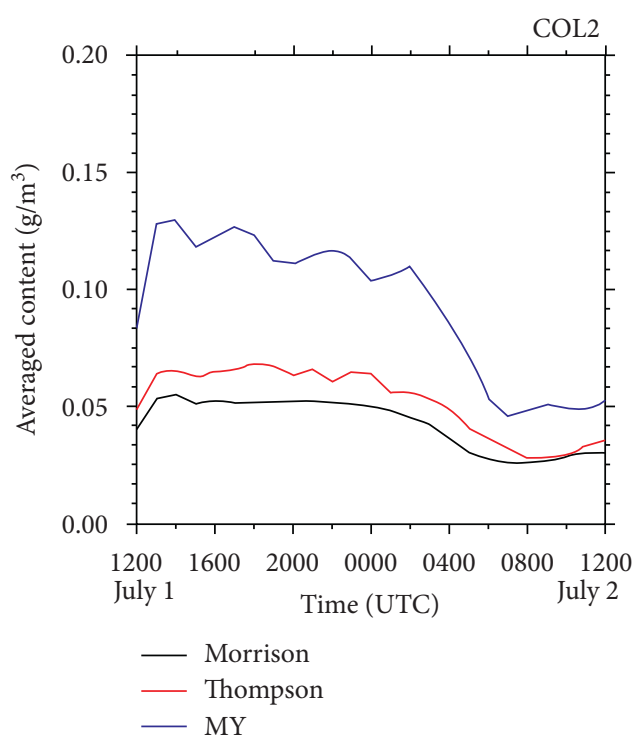

(d)

FIGURE 12: Time series of the mean contents of sink and source terms of ice-phase hydrometeors in heavy rainfall areas (R greater than $50 \mathrm{~mm} / 24$ (h) from 1200 UTC on 1 July to 1200 UTC on 2 July 2016: (a) melting of ice-phase hydrometeors; (b) deposition of vapor; (c) riming (for raindrops); (d) riming (for cloud droplets). The black, red, and blue lines indicate the Morrison, Thompson, and MY schemes, respectively.

TABLE 4: The same as Table 2 except for the melting of ice-phase hydrometeors (Mlt), deposition (Dep), and riming of raindrops (Col1) and cloud droplets (Col2) by ice-phase hydrometeors. "-" indicates a negligible change.

\begin{tabular}{|c|c|c|c|c|c|c|c|c|c|c|c|c|}
\hline \multirow{2}{*}{ Time } & \multicolumn{4}{|c|}{ Morrison } & \multicolumn{4}{|c|}{ Thompson } & \multicolumn{4}{|c|}{ MY } \\
\hline & Mlt & VD & Coll & Col2 & Mlt & $\mathrm{VD}$ & Col1 & $\mathrm{Col} 2$ & Mlt & $\mathrm{VD}$ & Col1 & $\mathrm{Col} 2$ \\
\hline $12 \mathrm{z} 01-13 \mathrm{z} 01$ & $\uparrow$ & $\uparrow$ & $\uparrow$ & $\uparrow$ & $\uparrow$ & $\uparrow$ & $\uparrow$ & $\uparrow$ & $\uparrow$ & $\uparrow$ & $\uparrow$ & $\uparrow$ \\
\hline $13 z 01-14 z 01$ & $\uparrow$ & $\uparrow$ & $\uparrow$ & $\uparrow$ & $\uparrow$ & $\uparrow$ & $\uparrow$ & $\uparrow$ & $\uparrow$ & $\uparrow$ & $\uparrow$ & $\uparrow$ \\
\hline $14 z 01-15 z 01$ & - & $\downarrow$ & - & $\downarrow$ & $\uparrow$ & $\downarrow$ & - & $\downarrow$ & $\downarrow$ & - & $\downarrow$ & $\downarrow$ \\
\hline 03Z02-04Z02 & $\downarrow$ & $\downarrow$ & $\downarrow$ & $\downarrow$ & $\downarrow$ & $\downarrow$ & $\downarrow$ & $\downarrow$ & $\downarrow$ & $\downarrow$ & $\downarrow$ & $\downarrow$ \\
\hline 04Z02-05Z02 & $\downarrow$ & $\downarrow$ & $\downarrow$ & $\downarrow$ & $\downarrow$ & $\downarrow$ & $\downarrow$ & $\downarrow$ & $\downarrow$ & $\downarrow$ & $\downarrow$ & $\downarrow$ \\
\hline 05Z02-06Z02 & $\downarrow$ & $\downarrow$ & $\downarrow$ & $\downarrow$ & $\downarrow$ & $\downarrow$ & $\downarrow$ & $\downarrow$ & $\downarrow$ & $\downarrow$ & $\downarrow$ & $\downarrow$ \\
\hline
\end{tabular}




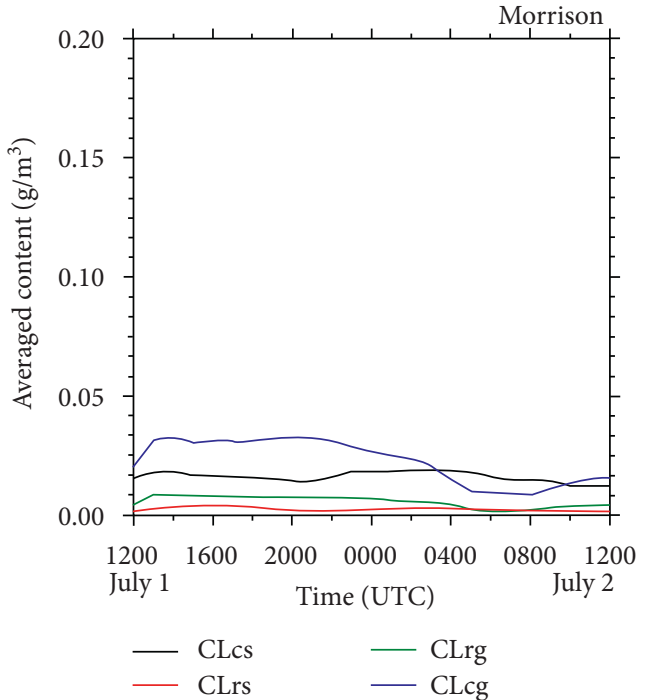

(a)

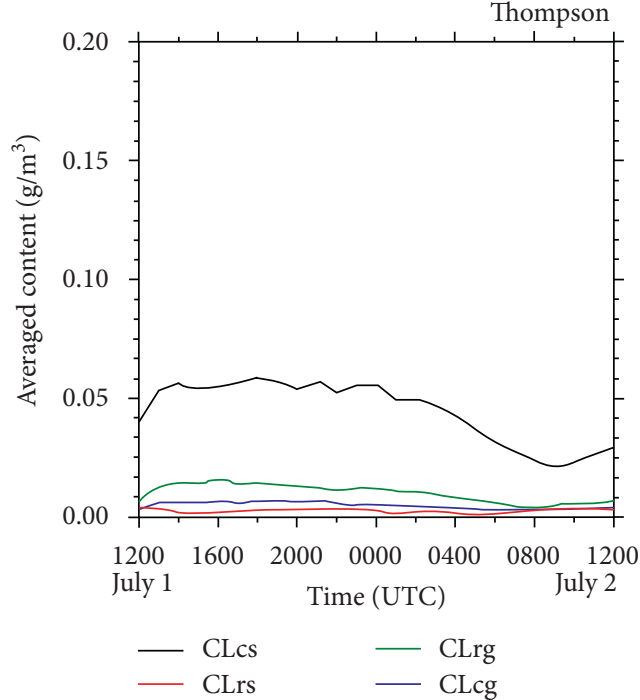

(b)

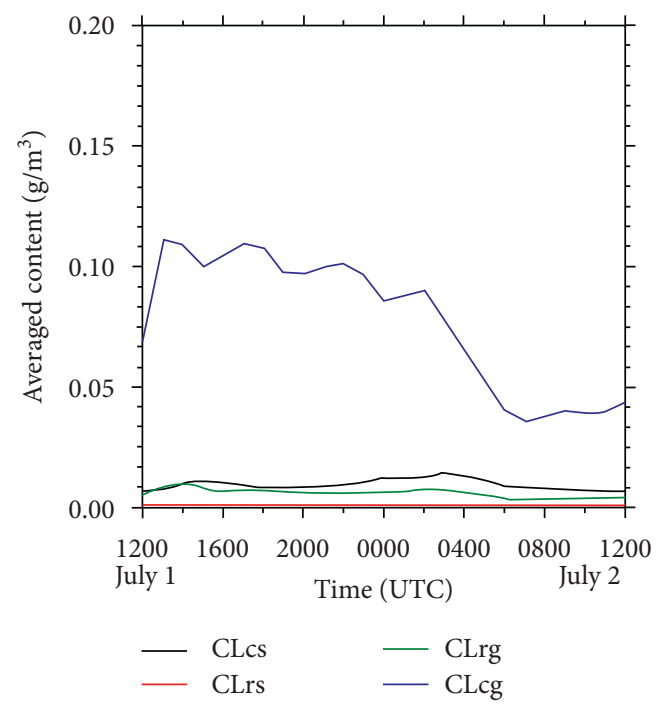

(c)

Figure 13: Time series of the mean contents of the riming process in heavy rainfall areas from 1200 UTC on 1 July to 1200 on 2 July 2016 : (a) Morrison; (b) Thompson; (c) MY. The black, red, green, and blue lines indicate cloud droplet-snow, raindrop-snow, cloud dropletgraupel, and raindrop-graupel interactions, respectively.

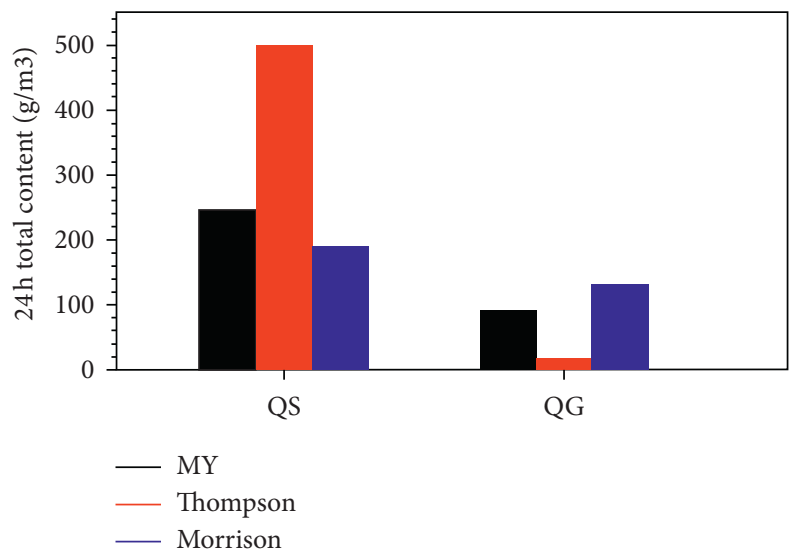

FIGURE 14: Vertically and domain-averaged contents of snow (QS) and graupel (QG) from three schemes in heavy rainfall areas from 1200 UTC on 1 July to 1200 UTC on 2 July 2016. 
in graupel and snow, which can cause differences in melting and thus affect the distribution of rainfall directly or indirectly.

\section{Summary and Conclusions}

Microphysical processes affecting Meiyu front precipitation in central-eastern China are complex and challenging to model. This study examined the sensitivity of a simulated Meiyu heavy rainfall event over central China to three different cloud microphysical parameterizations in the WRF model.

The general large-scale circulation and thermodynamic characteristics of the Meiyu rainfall case were reasonably reproduced by all the three experiments with different microphysics schemes. The overall distribution of the simulated precipitation matched well with that of the observations, while the average rainfall amount was overestimated, especially in heavy rainfall areas. The simulated rainfall in all three schemes began rapidly and gained strength at the very beginning but dissipated rapidly, while the observed precipitation began slowly but maintained a relatively steady intensity throughout the period. The more rapid evolution of the rainfall rate in the model was consistent with the greater-than-observation temporal variability in the geopotential height over central-eastern China. The simulated precipitation in the model experiments was also overestimated compared to observations from the South China Monsoon Rainfall Experiment [25], while the rainfall rate from all microphysics schemes was more than that of the observations for nearly the entire simulation period.

A microphysical budget analysis indicated that melting of ice-phase hydrometeors and accretion of cloud droplets by raindrops were the key processes contributing to the growth of raindrop and formation of heavy rainfall in the model. Bergeron and riming processes prevailed in the growth of ice-phase hydrometeors. The rapid changes in the microphysics budget terms with time in the model were consistent with the rapid evolution of rainfall with time in the model. Large differences in riming processes existed in the three schemes, leading to different distributions of icephase hydrometeors, especially for snow and graupel.

There are nearly 40 microphysical processes in each scheme. For some microphysical processes, there may be several different parameterization methods. Therefore, it is difficult to compare all processes at the same time in this study. Furthermore, the differences between schemes are not only due to different parameterizations but also due to the predefined hydrometeor characteristics (see Table 2). For example, although the mass production rates of cloud water are the same between two schemes, the number concentration will differ because the predefined distribution of cloud droplets differs [45]. This will lead to differences in collisions between cloud droplets and ice-phase hydrometeors which is a key microphysics process for the growth of graupel between the schemes. Therefore, it is difficult to conclude how the differences in the parameterizations of certain microphysics process affect the model results. Moreover, contributions from other factors, such as the assumed distribution of hydrometeors, should not be neglected.

Because of the complexity of dealing with all cloud microphysical processes, to avoid discussing the conversion between ice-phase hydrometeors, all frozen hydrometeors were classified into only one category for an initial comparison. After differences in the ice-phase processes were found, they were individually compared. Their direct effects impacted the distribution of ice-phase hydrometeors. It would be easy to judge which scheme is the best one when all hydrometeors can be distinguished correctly. However, it is difficult to deduce the hydrometeor types and amounts because the predefined characteristics of the hydrometeors lead to some uncertainties [46].

Which scheme could most accurately describe the cloud structure of heavy Meiyu rainfall? Regarding this question, from the comparison of the RMSE of accumulated rainfall over 24 hours, it appears that the Thompson scheme performed the best in this study. However, determining whether or not this scheme simulated the detailed microphysical structure of the clouds requires the simulated distribution of hydrometeors, especially ice-phase particles, to be compared with observations in the future. Field work and in situ, remote sensing observations of cloud micro- and macroproperties for Meiyu rainfall events in central-eastern China are needed.

\section{Data Availability}

The precipitation data used in this study were provided by the China Meteorological Administration. The global analysis dataset (FNL) was acquired from the National Centers for Environmental Prediction (https://www.ncep. noaa.gov/). The ERA5 reanalysis data used are from European Center for Medium-Range Weather Forecasts (https:// climate.copernicus.eu/climate-reanalysis). Data from LAPS are archived and distributed by the Institute of Heavy Rainfall, CMA, Wuhan, as part of the dataset during the Integrative Monsoon Frontal Rainfall Experiment (IMFRE) in 2018.

\section{Conflicts of Interest}

The authors declare that they have no conflicts of interest.

\section{Acknowledgments}

This research was supported by the NSFC project of Cloud Analysis and Microphysical Investigation of Meiyu Frontal System Based on Ground-Airborne Observations (41620104009), the National Natural Science Foundation of China (91637211 and 41905071), and Key Scientific and Technological Development Projects in Hubei Province in China (2018Z05).

\section{References}

[1] G. T.-J. Chen, C.-C. Wang, and D. T.-W. Lin, "Characteristics of low-level jets over northern taiwan in mei-yu season and 
their relationship to heavy rain events," Monthly Weather Review, vol. 133, no. 1, pp. 20-43, 2005.

[2] J. Sun, S. Zhao, G. Xu, and Q. Meng, "Study on a mesoscale convective vortex causing heavy rainfall during the mei-yu season in 2003," Advances in Atmospheric Sciences, vol. 27, no. 5, pp. 1193-1209, 2010.

[3] K. Kato and Y. Kodama, "Formation of the quasi-stationary baiu front to the south of the Japan islands in early may of 1979," Journal of the Meteorological Society of Japan. Ser. II, vol. 70, no. 1B, pp. 631-647, 1992.

[4] T. Sampe and S.-P. Xie, "Large-scale dynamics of the meiyubaiu rainband: environmental forcing by the westerly jet*," Journal of Climate, vol. 23, no. 1, pp. 113-134, 2010.

[5] K. Ninomiya and H. Muraki, "Large-scale circulations over East Asia during baiu period of 1979," Journal of the Meteorological Society of Japan. Ser. II, vol. 64, no. 3, pp. 409-429, 1986.

[6] Z. He, Q. Zhang, K. Zhao et al., "Initiation and evolution of elevated convection in a nocturnal squall line along the Meiyu front," Journal of Geophysical Research:Atmospheres, vol. 123, pp. 7292-7310, 2018.

[7] Y. Du, Z. Q. Xie, and Q. Miao, "Spatial scales of heavy Meiyu precipitation events in eastern China and associated atmospheric processes," Geophysical Research Letters, vol. 47, no. 11, 2020.

[8] J. Jiang and Y. Ni, "Diagnostic study on the structure characteristics of a typical Meiyu front system and its maintenance mechanism," Advances in Atmospheric Sciences, vol. 21, no. 5, pp. 802-813, 2004.

[9] R. Wu, S. Gao, and Z. Tan, Front Process and Mesoscale Disturbance. The Re-search of Formation Mechanisms and Predictive Theories of Major Weather Disasters in China as the Development Planning Project for National Key Fundamental Studies, in Chinese, p. 170, China Meteorological Press, Beijing, China2004, .

[10] Z. H. Yu, H. C. Lu, and X. Z. Fan, "An observational study of the Meso- $\beta$ scale moving systems in the Meiyu Front," Acta Meteorologica Sinica, vol. 2, no. 4, pp. 436-449, 1988.

[11] S. Kumar, A. Hazra, and B. N. Goswami, "Role of interaction between dynamics, thermodynamics and cloud microphysics on summer monsoon precipitating clouds over the Myanmar Coast and the Western Ghats," Climate Dynamics, vol. 43, no. 3-4, pp. 911-924, 2013.

[12] Y. Ni and X. Zhou, "Study on formation mechanisms of heavy rainfall within the Meiyu along the mid-lower Yangtze River and theories and methods of their detection and prediction," Journal of Meteorological Research, vol. 20, no. 2, pp. 191-208, 2006.

[13] J. Houghton, Y. Ding, J. Griggs et al., Climate Change: The Scientific Basis, p. 875, The Press Syndicate of the University of Cambridge, New York, NY, USA, 2001.

[14] L. R. Koenig, "Numerical modeling of ice deposition," Journal of the Atmospheric Sciences, vol. 28, no. 2, pp. 226-237, 1971.

[15] H. Morrison, J. A. Curry, and V. I. Khvorostyanov, "A new double-moment microphysics parameterization for application in cloud and climate models. Part I: Description," Journal of the Atmospheric Sciences, vol. 62, no. 6, pp. 1665-1677, 2005.

[16] J. A. Milbrandt and M. K. Yau, "A multimoment bulk microphysics parameterization. Part I: analysis of the role of the spectral shape parameter," Journal of the Atmospheric Sciences, vol. 62, no. 9, pp. 3051-3064, 2005a.

[17] J. A. Milbrandt and M. K. Yau, "A multimoment bulk microphysics parameterization. Part II: a proposed three-moment closure and scheme description," Journal of the Atmospheric Sciences, vol. 62, no. 9, pp. 3065-3081, 2005b.

[18] G. Thompson, P. R. Field, R. M. Rasmussen, and W. D. Hall, "Explicit forecasts of winter precipitation using an improved bulk microphysics scheme. Part II: implementation of a new snow parameterization," Monthly Weather Review, vol. 136, no. 12, pp. 5095-5115, 2008.

[19] H. Morrison and J. A. Milbrandt, "Parameterization of cloud microphysics based on the prediction of bulk ice particle properties. Part I: scheme description and idealized tests," Journal of the Atmospheric Sciences, vol. 72, no. 1, pp. 287-311, 2015.

[20] Y. Lin and B. A. Colle, "A new bulk microphysical scheme that includes riming intensity and temperature-dependent ice characteristics," Monthly Weather Review, vol. 139, no. 3, pp. 1013-1035, 2011.

[21] P. Wang and J. Yang, "Observation and numerical simulation of cloud physical processes associated with torrential rain of the Meiyu front," Advances in Atmospheric Sciences, vol. 20, no. 1, pp. 77-96, 2003.

[22] Y. Luo, H. Wang, Y. Zheng, and H. Morrison, "Modeling convective-stratiform precipitation processes on a Mei-Yu front with the Weather Research and Forecasting model: comparison with observations and sensitivity to cloud microphysics parameterizations," Journal of Geophysical Research: Atmospheres, vol. 115, no. D18, 2010.

[23] H. P. Dasari and R. Salgado, "Numerical modelling of heavy rainfall event over madeira island in Portugal: sensitivity to different micro physical processes," Meteorological Applications, vol. 22, no. 1, pp. 113-127, 2015.

[24] K. O. Chawla, P. Mujumadar, and Y. Ni, "Assessment of the weather research and forecasting (WRF) model for extreme rainfall event simulation in the upper Ganga Basin," $\mathrm{Hy}$ drology and Earth System Sciences Discussions, vol. 22, no. 2, pp. 1-29, 2017.

[25] K. FurtadoP. Field et al., "Cloud microphysical factors affecting simulations of deep convection during the presummer rainy season in southern China," Journal of Geophysical Research: Atmospheres, vol. 123, no. 18, pp. 10-477, 2018.

[26] C. Orr and M. Listowski, E. Couttet, W. Collier Immerzeel et al., "Sensitivity of simulated summer monsoonal precipitation in langtang valley, himalaya, to cloud microphysics schemes in wrf," Journal of Geophysical Research Atmospheres, vol. 122, no. 12, 2017.

[27] W. Gao, L. Liu, J. Li, and C. Lu, "The microphysical properties of convective precipitation over the Tibetan Plateau by a subkilometer resolution cloud-resolving simulation," Journal of Geophysical Research: Atmospheres, vol. 123, no. 6, pp. 3212-3227, 2018.

[28] J. Yin, D. Wang, and G. Zhai, "A comparative study of cloudprecipitation microphysical properties between East Asia and other regions," Journal of the Meteorological Society of Japan. Ser. II, vol. 91, no. 4, pp. 507-526, 2013.

[29] Q. Tang, H. Xiao, C. Guo, and L. Feng, "Characteristics of the raindrop size distributions and their retrieved polarimetric radar parameters in northern and southern China," Atmospheric Research, vol. 135-136, no. 1, pp. 59-75, 2014.

[30] Y. Ding and J. Chan, "The East Asian summer monsoon: an overview," Meteorology and Atmospheric Physics, vol. 89, no. 1-4, pp. 117-142, 2005.

[31] K. Ninomiya and Y. Shibagaki, "Multi-scale features of the Meiyu-Baiu front and associated precipitation systems," Journal of the Meteorological Society of Japan, vol. 85B, no. 7, pp. 103-122, 2007. 
[32] S. C. Albers, J. A. Mcginley, and D. L. Birkenheuer, "The local analysis and prediction system (LAPS): analyses of clouds, precipitation, and temperature," Weather and Forecasting, vol. 11, no. 3, pp. 273-287, 1996.

[33] H. Smart, C. Chunguang, and W. Zhibin, "Scientific designs, functions and applications of LAPS," Torrential Rain and Disasters, vol. 28, no. 1, pp. 64-70, 2009, in Chinese.

[34] Y. Ni, C. Cui, H. Li et al., "High-resolution mesoscale analysis data from the South China heavy rainfall experiment (SCHeREX): data generation and quality evaluation," Acta Meteorologica Sinica, vol. 25, no. 4, pp. 478-493, 2011.

[35] Y. Liu, C. Chen, and J. Xu, "Comparison of precipitation forecast in central China with different boundary layer parameterizations," Torrential Rain and Disaster, vol. 34, no. 3, pp. 230-238, 2015, in Chinese.

[36] Y. Li, Y. Deng, Y. Song, and H. Zhang, "Multi-scale temporospatial variability of the East Asian Meiyu-Baiu fronts: characterization with a suite of new objective indices," Climate Dynamics, vol. 51, no. 5-6, pp. 1659-1670, 2018.

[37] Y. Huang, Y. Wang, and X. Cui, "Differences between convective and stratiform precipitation budgets in a torrential rainfall event," Advances in Atmospheric Sciences, vol. 36, no. 5, pp. 495-509, 2019.

[38] X. Cui and X. Li, "Role of surface evaporation in surface rainfall processes," Journal of Geophysical Research: Atmospheres, vol. 111, no. D17, 2006.

[39] X. Li, "Cloud microphysical and precipitation responses to a large-scale forcing in the tropical deep convective regime," Meteorology and Atmospheric Physics, vol. 94, no. 1-4, pp. 87-102, 2006.

[40] J.-J. Wang, X. Li, and L. D. Carey, "Evolution, structure, cloud microphysical, and surface rainfall processes of monsoon convection during the South China Sea Monsoon Experiment," Journal of the Atmospheric Sciences, vol. 64, no. 2, pp. 360-380, 2007.

[41] X. Cui, "A cloud-resolving modeling study of diurnal variations of tropical convective and stratiform rainfall," Journal of Geophysical Research: Atmospheres, D2, vol. 113, 2008.

[42] X. Cui and X. Li, "A cloud-resolving modeling study of shortterm surface rainfall processes," Meteorology and Atmospheric Physics, vol. 111, no. 1-2, pp. 1-11, 2011.

[43] S. Yang and S. W. Nesbitt, "Statistical properties of precipitation as observed by the trmm precipitation radar," Geophysical Research Letters, vol. 41, no. 15, pp. 5636-5643, 2014.

[44] H. J. Song and B. J. Sohn, "An evaluation of wrf microphysics schemes for simulating the warm-type heavy rain over the Korean peninsula," Asia-Pacific Journal of Atmospheric Sciences, vol. 54, no. 2, pp. 1-12, 2018.

[45] J.-W. Bao, S. A. Michelson, and E. D. Grell, "Microphysical process comparison of Three microphysics parameterization schemes in the WRF Model for an idealized squall-line case study," Monthly Weather Review, vol. 147, no. 9, pp. 3093-3120, 2019.

[46] J. M. Straka, D. S. Zrnić, and A. V. Ryzhkov, "Bulk hydrometeor classification and quantification using polarimetric radar data: synthesis of relations," Journal of Applied Meteorology, vol. 39, no. 8, pp. 1341-1372, 2000. 